Sergio Zañartu, S.J.

Facultad de Teología de la

Pontificia Universidad Católica de Chile

\title{
El Concilio de Constantinopla I y el proceso previo. Algunas anotaciones
}

\section{UN CONCILIO ORIENTAL}

La gran controversia trinitaria, que conmovió a la Iglesia durante el s. IV, alcanzó una formulación griega satisfactoria en torno al primer Concilio de Constantinopla, el año 381. Este fue un concilio oriental, posteriormente reconocido como ecuménico. No todos los obispos de Oriente fueron invitados. Solo promediado el Concilio, se hicieron presentes dos obispos de Egipto (el de Alejandría y otro) y uno de Occidente (el de Tesalónica), impugnando la legitimidad de Gregorio de Nacianzo como obispo de Constantinopla, quien proponía la aceptación de Paulino, reconocido justamente por Roma y Alejandría, como el obispo de Antioquía. Ante esto, Gregorio de Nacianzo renunció. Por otro lado, los obispos macedonianos (1), que no aceptaban la divinidad del Espíritu, se retiraron, pese a la redacción algo 'conciliadora' del Credo.

Perdido el documento dogmático, su fórmula trinitaria (una ovoı $\alpha$ y tres

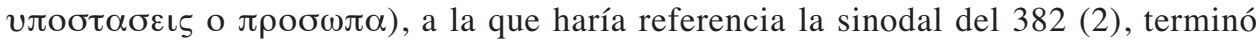
con la crisis arriana de Oriente, en parte gracias a los edictos del emperador Teodo-

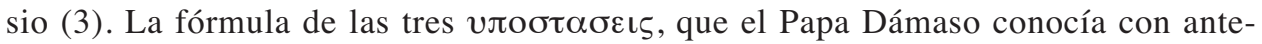

(1) Aparecen condenados como semiarrianos o pneumatómacos en el canon 1 del Concilio.

(2) En ella, en la que se habla del Constantinopolitano I, que siguió la fe de Nicea, conforme al mandato de Cristo sobre el bautismo, se dice lo siguiente: "creer en el nombre del Padre y del Hijo y del Espíritu Santo, de tal forma que se crea en una sola divinidad, una potestad, una substancia del Padre y del Hijo y del Espíritu Santo, y una igual honra, dignidad y señorío coeterno en tres hypóstasis perfectas o tres personas ( $\pi \rho 0 \sigma \omega \pi \circ \iota \varsigma$ ) perfectas; de suerte que la peste de Sabelio, que confunde las hypóstasis o suprime las propiedades, no encuentre lugar, ni tampoco florezca la blasfemia de los Eunomianos, de los arrianos y de los pneumatómacos, que parten la substancia o naturaleza o la divinidad y que introducen en la Trinidad increada, con-

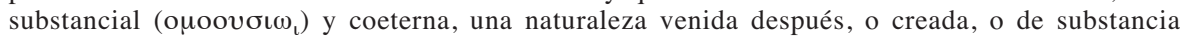
diferente" (Teodoreto, Hist eccles, V, 9, 11, GCS 19, p. 292).

(3) Este, ya en el edicto de Tesalónica del 380, había impuesto la fe de Roma y Alejandría. Pero llegado a Constantinopla se acercó a Melecio de Antioquía, que no era reconocido por Roma. Confirmó la fe del Concilio de Constantinopla I con edicto del 30 de julio de 381 .

Fue mucha la influencia del poder imperial en la crisis arriana, así por ejemplo, hizo cambiar el resultado en los concilios de Rimini, etc. La razón política impulsaba a los emperadores a buscar la paz apoyando lo que ellos creían líneas medias. Este apoyo político se prestaba a variadas 
rioridad (4), no había sido acogida por este (5). Los occidentales mantenían el anatematismo del concilio de Nicea: el Hijo no era de una hipóstasis distinta del Padre. Así lo confirmaron durante el concilio de Sárdica del 343. Igualmente el cisma occidental luciferiano, donde militaban los nicenos intransigentes, continuó rechazando las tres hipóstasis de los orientales, que Atanasio en el Tomo a los Antioquenos del concilio de Alejandría del 362 (6), buscando un frente común con los homoio-ousianos, ya había aceptado como de alguna manera 'equivalente', a su fórmula 'una hipóstasis'. En Occidente, solo Hilario de Poitiers, buscando ese mismo frente común, en su De synodis, había defendido cierta equivalencia de la fórmula nicena, tan asentada en Occidente, con la semejanza 'según la substancia' (semejanza en todo) de varios concilios orientales. Es decir, no se necesitaba ser niceno para confesar la verdadera divinidad del Hijo (7). A esto hay que añadir que si hipóstasis se traducía por substancia, la fórmula en latín quedaba: tres substancias

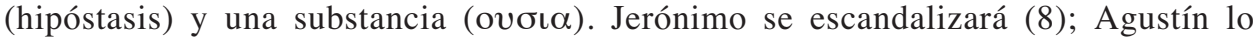
atribuirá a alguna peculiaridad del lenguaje griego (9). Occidente tradicionalmente

intrigas, como las acusaciones contra Atanasio. Los filoarrianos a veces se equivocaron en la entronización de obipos, como en el caso de Cirilo de Jerusalén y de Melecio de Antioquía. Para Atanasio la persecución llegó a ser peor que la de los emperadores paganos; llegó a ver en Constancio un anticristo. Osio escribe a Constancio que se debe dar al César lo del César y a Dios lo que es de Dios (Atanasio, Hist Ar, 44). Respecto a Hilario concluye H. C. Brennecke (Hilarius von Poitiers und die Bischofsopposition gegen Konstantius II. Untersuchungen zur dritten Phase des arianischen Streites (337-361) (Patristische Texte und Studien, 26), Berlin 1984, p. 371): "bildet das Verhältnis zwischen Staat und Kirche noch kein Problem. Staatliche Macht kann und soll nach seiner Meinung für das als 'orthodox' Erkannte eingesetzt werden, also gegen alle Häresie".

(4) Cf. p. e. Jerónimo, Ep 15; Basilio, Ep 263, 5.

(5) Un concilio de Iliria del $377 / 378$ sería el primer testimonio occidental a favor de las tres

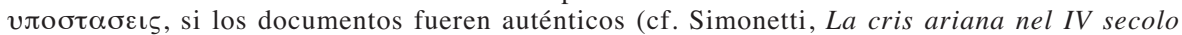
(Studia Ephemeridis ‘Augustinianum', 11), Roma 1975, pp. 439-441; A. de Halleux, 'Hypostase' et 'Personne' dans la formation du dogme trinitaire (ca 375-381), pp. 177-179, en idem, Patrologie et oecuménisme. Recueil d'études (Biblioteca Ephemeridum Theologicarum Lovaniensium, 93), Leuven 1990, pp. 113-214). Recordemos que un siglo antes el Papa Dionisio había combatido las tres hipóstasis de Dionisio de Alejandría. Según él, extrañas y separadas

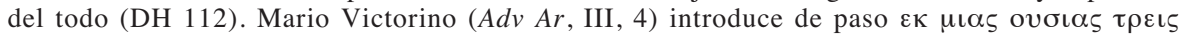

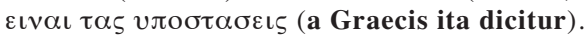

(6) Núm. 5s. Véase también Atanasio, De synodis, 41.

(7) Para Occidente, en general, se necesitaba ser atanasiano para ser ortodoxo.

(8) Cf. Ep 15.

(9) Cf. De Trin, VII, 6 (10s), 1-6. Véase, p. e.: Ib. V, 8 (10), 43-51; VII, 4 (7), 1-6; VII, 4 (8), $112-$ 117. Gregorio de Nacianzo valorará la peculiaridad del lenguaje griego respecto a esta expresión frente a la pobreza del lenguaje de los itálicos (Orat, 21, 35). G. L. Prestige (God in Patristic Thought, London 1952, p. 235) llegará a expresar: "To the Greeks, God is one objective Being, though $\mathrm{He}$ is also three Objects. This view of the matter differs in conception, though not in effect, from the Latin view, according to which God is one Object and three Subjects (una substancia, tres personae)". "La dimension subjective et dialogale, à laquelle la théologie trinitaire se montre aujourd'hui si justement attentive, ne faisait pas l'objet des controverses du IVe siècle. L'enjeu dgmatique que 1'orthodoxie disputait alors à l'arianisme et au sabellianisme portait exclusivement sur le paradoxe de la distinction et de l'union d'un Dieu considéré comme la Réalité transcendante plutôt que comme le Sujet absolu. C'est pourquoi les hypostases ellesmêmes étaient comprises comme trois objets, ou modes d'être objectifs, plutôt que comme trois modes d'existence ou personnes en communion. La 'révolution de l'ontologie' trop généreusement attribuée aux Pères cappadociens n'inaugure donc pas le personnalisme au sens actuel du terme" (A. de Halleux, Personnalisme ou essentialisme trinitaire chez les Pères Cappadociens?, p. 266, en Id., Patrologie et oecuménisme, 215-268). 
se expresará con tres personas y una substancia (10). Por último, el credo del Constantinopolitano (11), credo básico de las Iglesias cristianas, Occidente solo lo conoció cuando se leyó en el concilio de Calcedonia, después que ya Agustín había desarrollado el Filioque, que terminó imponiéndose en Occidente. En resumen, el Constantinopolitano I fue un concilio oriental (12), que posteriormente fue reconocido como ecuménico. Observemos primero su expresión de la divinidad del Espíritu, y después su fórmula trinitaria.

\section{RESPECTO A LA DIVINIDAD DEL ESPÍRITU SANTO}

Creo que es clara la divinidad del Espíritu en el N. T., por las obras de 'divinización' que este realiza. Las obras serán un gran argumento para Atanasio en su $1^{a}$ Ep. ad Serapionem. Pero lo que tenía que probarse, es que fuera distinto de Dios, el Padre, y no una mera fuerza de Él. En cambio, que el Hijo, el encarnado, fuera distinto, era evidente, y lo que había que probar en su caso, era que fuera Dios y no un simple hombre adoptado en grado eminente. Así en el N. T. asistimos a una progresiva toma de conciencia respecto de la divinidad verdadera de Jesús, el Señor, el Hijo. Ahora bien, ¿por qué el Espíritu era distinto de Dios? Porque es el Espíritu del Padre y del Hijo: el Hijo lo recibe del Padre y lo derrama sobre nosotros. Porque es el Paráclito que viene cuando el Hijo se va, etc. Y así queda plasmado como tercero en algunas fórmulas, sobre todo en la del bautismo. Por eso, hasta la mitad del s. IV los cristianos lo formularon en fórmulas ternarias, p. e. Gloria al Padre

(10) Esto viene de Tertuliano. Mario Victorino rechaza 'persona' porque le parece modalista ( $A d v A r$, I, 11.41). A Agustín no le gusta por la razón contraria, porque es un absoluto y no un relativo, y los absolutos en Dios son uno. Cf. p. e.: De Trin V, 9 (10), 1-11; VII, 4ss (7ss), 56ss; VII, 6 (11), 20-33; VIII, prooem (1), 1-22.

En la conclusión de su libro (La crisi, 559s) afirma Simonetti: "Alla fine del IV secolo vediamo invece imporsi in argomento trinitario una vera e propria koiné teologica. In Oriente essa si sintetizza nella dottrina che afferma una ousia e tre ipostasi nella Trinità, una formula di compromesso -come abbiamo rilevato- fra il monarchianismo di tradizione asiatica e il pluralismo (dottrina delle ipostasi) di tradizione alessandrina... Principalmente all'autorità di Atanasio fu dovuta la sopravvivenza di fondamentali istanze monarchiane insistenti sull'unità di Dio, contenute nel credo niceno; di qui esse confluirono nella sintesi dei Cappadoci, temperando in senso più accentuatamente unitario il pluralismo insito nella dottrina delle tre ipostasi, per forza di cosa più attenta a rilevare la distinzione delle persone che non l'unità di Dio. A tale impostazione trinitaria corrisponde in Occidente quella insistente sulla formula una natura (substantia) / tre personae, che, pur attraverso uno sviluppo tutt'altro che parallelo a quello della formula orientale una ousia / tre ipostasi, finì per assumerne con Ilario ed Ambrogio la stessa fondamentale significazione.

(11) H. C. Brennecke (Konstantinopel. Ökumenische Konzilien. 1. Konzil von 381, LThK, $3^{\mathrm{a}}$ ed., VI, 312s, col. 313) afirma respecto al símbolo de Constantinopla: "Besonders unklar hinsichtlich seiner Zugehörigkeit zur Synode ist das ihr in der Tradition zugeschriebene Bekenntnis (NicaenoKonstantinopolitanisches Glaubensbekenntnis), das erst in Chalkedon 451 als Ergänzung und Bestätigung des Nicaenums der Synode von 381 zugeordnet wird, was heute mehrheitlich akzeptiert wird. Umstritten ist, ob es zur dogmatischen Definition oder nur in die Auseinandersetzung mit den Pneumatomachen gehörte, ob und inwieweit die antiochienische Meletianersynode von 379 unter Aufnahme auch westlichen Formulierungen die Vorlage geliefert hatte". Cf. J. N. D. Kelly, Primitivos Credos cristianos, trad. de $3^{\mathrm{a}}$ ed., Salamanca 1980, cap. 10.

(12) Puede verse a este respecto la opinión de A. de Halleux en Le Ile concile oecuménique. Une évaluation dogmatique et ecclésiologique, Cristian. nella storia 3(1982)297-327. 
por el Hijo en el Espíritu. Por otra parte, lo siguieron vivenciando como la fuerza divina de la inspiración y de la santificación.

Si costaba a los apologistas formular el Logos inmanente (y no solo el Logos en torno a la creación) como ya distinto del Padre, también seguía costando a veces concebir el Espíritu como distinto, dado que se centraban en Dios y su Logos (Hijo), a lo que confluía que Dios fuera espíritu $(\mathrm{Jn} 4,24)$ o que el Hijo fuera espíritu según una cristología pneumática. Pero, aceptada la distinción, algunos autores tuvieron al Espíritu como una creatura, p. e. Eusebio de Cesarea (13). Si todo fue creado por el Logos (Jn 1, 3), luego también el Espíritu (14). Para los arrianos era la primera creatura hecha mediante el Logos (15), siendo el Logos el único creado directamente por el Padre. El debate inmediato posniceno se centró en la divinidad del Logos, siendo apenas mencionado el Espíritu, como en el Credo de Nicea. Se cumplía en la historia del dogma la progresión que Gregorio de Nacianzo atribuye a la revelación de Dios: primero tiene que asentarse un solo Dios, después el Hijo verdadero Dios y finalmente el Espíritu (16). Así, asentada la divinidad del Hijo, se comienza a preguntar por la del Espíritu. De hecho, la divinidad del Hijo va a arrastrar la del Espíritu, según la nivelación de la fórmula del bautismo. Este problema de la divinidad del Espíritu será ahora reducido y durará relativamente muy poco. El medio monástico había ya desarrollado la experiencia del Espíritu. Con la divinidad del Espíritu, se entra de lleno a considerar la Trinidad.

Los homeousianos (semejanza según la substancia, del Hijo con el Padre) comenzaron a considerar el Espíritu por el año 360 (17). Para varios de ellos, es decir para los macedonianos, que el Espíritu fuera creatura calzaba con la cultura de la época: Dios, Dios Hijo mediador, creatura (18). Correspondía a un esquema platónico descendente. Que el escenario hubiera estado hasta entonces centrado en Dios y el Hijo, y recién se comenzara a tratar más a fondo del Espíritu, se debería también en parte a que este ofrecía un problema especial: el Espíritu presenta menos rostro porque es el que penetra en nuestro interior, es más imprevisible (como el viento en

(13) Praep evang, XI, 20, 1; Eccl Theol, III, 6. Respecto a Orígenes, afirma Simonetti (La crisi, 13, cf. Ib., 363):" Molto meno preciso sull'origine dello Spirito santo, Origene tende a presentarla como creazione ad opera del Figlio per volontà del Padre, ma grazie ad un'operazione che anch'essa debe essere concepita $a b$ aeterno". Y en p. 495 n. 95, añade este autor: "Ma per creazione Origene in sostanza intendeva soltanto che lo Spirito santo aveva tratto origine dal Padre non direttamente come il Figlio (=generazione) ma per tramite del Figlio stesso. Infatti Origene non ha dubbi ad attribuire allo Spirito santo le prerogative della divinità... In Princ. I praef., 4 Origene aveva rilevato la carenza di dati tradizionali circa l'origine dello Spirito santo".

(14) Véase la respuesta de Gregorio de Nacianzo en Orat, 31, 12.

(15) Según ellos, el Espíritu tampoco era creador. "Quanto al rapporto fra divinità e attività creatrice, è più esatto dire che ariani e macedoniani sono portati a negare la divinità dello Spirito proprio in quanto negano la sua attività creatrice (i due argomenti sembrano condizionarsi a vicenda)" (Simonetti, La crisi, p. 484 n. 7).

(16) Orat 31, 26s.

(17) Cf. p. e. C. PIETRI, Le débat pneumatologique à la veille du Concile de Constantinople (358381), en Credo in Spiritum Sanctum. Atti del Congresso Teologico Internazionale di Pneumatologia, Roma 1983, pp. 55-87.

(18) Los macedonianos rechazaban el opoovoıs, pero afirmaban la semejanza perfecta del Hijo (opotovoเos). "Quanto allo Spirito santo, sembra che alcuni di loro lo abbiano definito come una creatura, ma altri preferivano rimanere nel vago: lo riconoscevano como thếon, non però come vero e propio Dio" (M. Simonetti, Macedonio (macedoniani), DPAC, col. 2062). 
la antigüedad), es, por tanto, más difícil de 'configurar'. Por otro lado, lo último que un sujeto suele ver, muchas veces es justamente lo más próximo a él, lo que está implicado en su mismo acto de ver. En este sentido parece lógico que la última reflexión trinitaria sea respecto a lo más cercano, en cierta forma, al sujeto creyente (19). Además en griego $\pi v \varepsilon v \mu \alpha$ es de género neutro, lo que es menos personalizante (20).

Del Hijo costó que se afirmara, conforme al credo de Nicea, que era engendrado y no creado, porque, en nuestra experiencia, todo lo engendrado es creado. Además, todo lo engendrado viene con posterioridad. Así los arrianos dirán que hubo un 'tiempo' que no era y en que el Padre no era Padre (21). Los ortodoxos responderán que la generación del Hijo es un misterio, que no sucede como entre los hombres, que el Padre es mayor que el Hijo solo en cuanto principio (22), pero no es anterior cronológicamente; que el Hijo es engendrado desde siempre. Dios es inmutable y siempre ha sido Padre, luego eternamente ha tenido un Hijo. Es absurdo hablar de un ' $\pi 0 \tau \varepsilon$ ' 'temporal' antes del tiempo, dado que los arrianos admitían que fue creado antes de los siglos, $\alpha \chi \rho o v \omega s$. Los arrianos dirán que el Padre es el

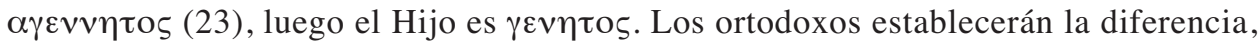
entre $\alpha \gamma \varepsilon v \nu \eta \tau o \varsigma$ (ingénito) y $\alpha \gamma \varepsilon v \eta \tau o \varsigma$ (increado). Por tanto el Hijo puede a la vez ser $\alpha \gamma \varepsilon v \eta \tau o \varsigma$ (y $\alpha v \alpha \rho \chi 0 \varsigma$ ) en cuanto Dios, y $\gamma \varepsilon v \vee \eta \tau o \varsigma$ en cuanto Hijo (con $\alpha \rho \chi \eta$ y $\alpha \iota \tau \iota \alpha)$, lo que tampoco corresponde a nuestra experiencia humana (24). Por tanto, $\alpha \gamma \varepsilon v v \eta \tau o \varsigma$ no es la definición (25) de la esencia divina, que no conocemos, sino lo que caracteriza al Padre (26). Los arrianos argüirán que Dios no puede engendrar, porque perdería substancia y se mutaría (padecería). Los ortodoxos responderán que la generación divina no es como la animal, sino un misterio indecible (27); que el Padre da todo al Hijo menos ser Padre (28). Luego toda la paternidad está en el

(19) En el Espíritu se contempla a Cristo. Recordemos, además, que 'espíritu' también se usa para el espíritu del hombre, con el que, por lo demás, nos 'conectamos' a Dios. Durante siglos en Occidente el Espíritu pudo estar como marginado de muchos medios cristianos (p. e. canon I de la misa sin epíclesis explícita del Espíritu, etc.), porque el occidental goza con lo visible, lo práctico, lo legal. Así le resaltaba el Padre, el Hijo y la Iglesia. Además el Espíritu, aunque sea el creador de unidad, puede ser a ratos un poco subversivo o prestarse para el iluminismo.

(20) Recordemos el juego de palabras de los Padres para expresar la unidad y diferencia en Dios: el Padre y el Hijo son lo mismo, pero no el mismo.

(21) En esto están reconociendo que Padre implica Hijo.

(22) O en cuanto este es encarnado.

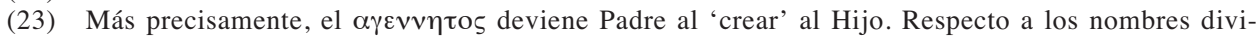
nos, un resumen de lo que dice Eunomio y responden Basilio y Gregorio de Nisa, puede consultarse en Simonetti, La crisi, 462-468.

(24) Gregorio de Nacianzo (Orat 29, 10) precisará que inengendrado y engendrado no dividen la substancia, sino que se dividen respecto a la substancia ( $\pi \varepsilon \rho \iota \tau \eta v \alpha v \tau \eta v$ ovoı $\alpha v)$. Diríamos que es la misma naturaleza.

(25) Además es un término negativo.

(26) Según algún autor, a Eunomio que caracterizaba a Dios como ingénito, respondería Gregorio de Nisa con la infinitud. Véase, p. e., A. M. Ritter, Dogma und Lehre in der Alten Kirche, p. 205s, en C. Andresen et alii, Die Lehrentwicklung im Rahmen der Katholizität (Handbuch der Dogmenund Theologiegeschichte, I), Göttingen 1989 (Nachdruck), pp. 99-283.

(27) A Dios solo lo conocemos por las operaciones. Según Arrio el Hijo no puede comprender al Padre (cf. p. e., Atanasio, C Arianos, I, 6; De synodis, 15; véase Ib., 36; Ep ad episc Aeg et Lib, 12).

(28) Todo lo del Padre es del Hijo (Jn 16, 15; 17, 10). Cf. p. e. Atanasio, De synodis, 49. 
Padre y toda la filiación en el Hijo (29). Por tanto, el Padre no pierde nada de su paternidad. No es así entre los hombres, en que el hijo a su vez pasará a ser padre de otros, siendo hijo y padre a la vez (30). Ilustración será, entre otras, la luz y el resplandor (31).

Los arrianos dirán que Padre o es nombre de substancia y el Hijo otra substancia o es nombre de acción (32) y el Hijo posterior. Los ortodoxos responderán que es nombre de relación, y no accidental porque en Dios todo es inmutable, no hay accidentes. Los arrianos argumentaran que si procede por voluntad del Padre es posterior a esta voluntad, que por lo demás pudo no tener. Los ortodoxos responderán que Dios está más allá de la contraposición entre voluntario y necesario (33). Los arrianos, en su argumentación, concluirán que es una creatura eminente (34), por tanto no como las otras, y que se la puede llamar dios (35); pero no lo es verdaderamente sino que es desemejante. Los ortodoxos responderán que no viene de la nada sino de la substancia del Padre (36), que le es opoovoıs (37). Los arrianos probarán la inferioridad del Logos por los sufrimientos de Cristo, porque es el Logos el que los sufre muy directamente (diríamos en su llamada

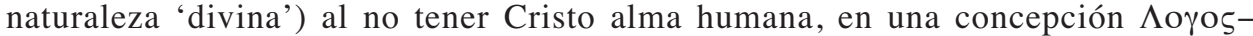
$\sigma \alpha \rho \xi$, que compartían varios 'ortodoxos'. Los ortodoxos responderán que lo que implica inferioridad se aplica a lo humano de Cristo, a la forma servi como insistirá Agustín, la cual lógicamente tiene alma (38). Y en este sentido interpretarán todos los dichos de la Escritura que connoten inferioridad, incluido $\operatorname{Pr} 8,22$

(29) En Adv Ar et Sab (11, GNO III, 1, 82, 24s), obra de controvertida autenticidad, se dirá: Porque es necesario que sea perfecto el Hijo de un Padre perfecto.

(30) Cf. p. e. Atanasio, 1Serap, 16; 4Serap, 6.

(31) Atanasio pedirá a los herejes que separen si pueden el resplandor de la luz (cf. 1Serap, 20; véase $C$ Arian II, 32; De decretis, 23s; De sent Dion, 24; Ep ad episc Aeg et Lib, 13, etc.). El símbolo de Nicea y el de Constantinopla dicen: luz de luz. Véase Atanasio, De sent Dion, 15; y la negación arriana ( $\lambda v \chi v o v$ a 0 o $\lambda v \chi v o v)$ en carta a Alejandro (Atanasio, De synodis, 16). Cf. $\mathrm{Hb}$ 1,3 .

(32) Cf. Gregorio de Nacianzo, Orat 29, 16.

(33) Respecto al caso de Atanasio en sus Orationes adversus Arianos, puede verse R. Schwager, Fluch und Sterblichkeit-Opfer und Unsterblichkeit. Zur Erlösungslehre des Athanasius, ZKT 103(1981)377-399, p. 381s. Sobre su distinción entre el Logos eterno y la creación libre, dice p. e. G. Florovsky: "The main demarcartion line passes between the Creator and the Creation, and not between the Father and the Son, as Arians contended (The Concept of Creation in Saint Athanasius, en Studia Patristica VI (Oxford 1959), pp. 36-57, p. 47).

(34) La única creada directamente por el Padre para crear mediante ella al mundo.

(35) Los hombres en la Escritura también son llamados dios. Al Logos, de sí mudable, se lo glorificaría como hijo de Dios desde el comienzo por su progreso moral, que era preconocido por Dios (cf. p. e. Alejandro, Ep ad Alexandrum (de Tesalónica), 11-13 (Teodoreto, Hist eccl, I, 4); Atanasio, C Arian, I, 5.35ss; De decretis..., 6; Ep ad epic Aeg et Lib, 12 ).

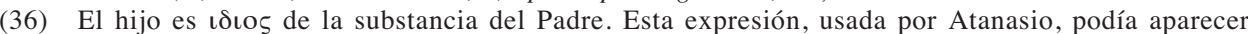
como modalista (cf. R. D. Williams, The Logic of Arianism, JThS 34(1983)56-81, pp. 58-62.

(37) Mario Victorino ( $A d v A r, \mathrm{IV}, 10)$ interpretará de la siguiente forma: "Unde una eademque subs-

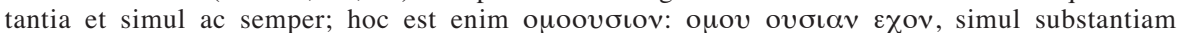
habens".

(38) Que lo humano sea alma y cuerpo, será destacado especialmente por antioquenos y occidentales, porque lo no asumido no es redimido, aunque el valor de la redención viene por la unión con el Logos. 
(39). Los ortodoxos argüirán fuertemente por la Escritura con textos como Jn 10, 30 (40); y porque es creador, nos diviniza, etc. La imagen perfecta que el Hijo es del Padre, denota la misma substancia. Y no es desemejante, porque todo hijo es semejante a su padre. Los ortodoxos argüirán, siguiendo a los apologistas, que Dios siempre tuvo Logos, Sabiduría (41). Los arrianos lo concederán, pero como inmanente y no distinto del Padre; en cambio, el Logos que tomará carne, es creado (42). Pero a los arrianos que distinguen la creación del Logos unigénito (directamente por el Padre (43)) de las demás creaturas (creadas mediante el Logos), Atanasio les preguntará mediante quién fue creado el Logos, dado que toda la creación ha necesitado un intermediario para ser creada, pregunta que conduciría a un recurso al infinito (44).

Estas y otras objeciones y respuestas se agitaron en la polémica de la crisis arriana que duró más de 50 años. Pero volvamos al dilema inicial para aplicarlo al Espíritu. El Hijo, Dios unigénito, es engendrado y no creado. Visto esto, los pneumatómacos arguyen que si el Espíritu no es creado, tendría que ser también engendrado (45), hijo o nieto del Padre (46). Por lo tanto es creado, aunque la primera de las creaturas del Hijo. La fe, para expresarse, y paralelamente a lo que pasó con el Unigénito que no era creatura, tiene que dar un paso más, y así señala un tercer camino en el misterio de Dios, que tampoco corresponde a la experiencia humana: el Espíritu procede y no como hijo. Para eso toma la expresión de Jn 15, 26, عклo$\varepsilon v \varepsilon \tau \alpha \iota$, que en ese momento todavía no es técnica (exclusiva del Espíritu) (47),

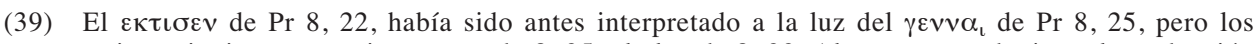
arrianos invierten esto, interpretando 8, 25 a la luz de 8,22. Alguno responderá que la traducción debería decir $\varepsilon \kappa \tau \eta \sigma \alpha \tau o$, o que eso no se aplica a Cristo. Respecto a otros textos de la Escritura, cf. p. e. Gregorio de Nacianzo, Orat 29, 18. Véase Simonetti, La crisi, p. e.: 52s; 259; 475-480. También puede consultarse, R. P. C. Hanson, The Search for the Christian Doctrine of God. The Arian Controversy 318-381, Edinburgh 1993 reprinted, cap. 24, 1.

(40) Cf. Mt 28, 19; Jn 1, 1-3; 10, 38; 12, 45; 14, 9s.20; 16, 15; 17, 10; Rm 9, 5; Flp 2, 6; Hb 1, 2s; 1 Jn 5,20 , etc.

(41) Si actualmente podemos decir que el mundo plural tiene como condición de posibilidad que en Dios haya distinción, Trinidad, quizás en línea análoga los Padres pensaban, desde el orden del mundo, que en Dios tiene que haber un Logos eterno, ordenador del cosmos, distinto del Padre. Es verdad que algunos apologistas habían tendido a un Logos $\varepsilon v \delta \iota \alpha \theta \varepsilon \tau o s$ no distinto, y a un

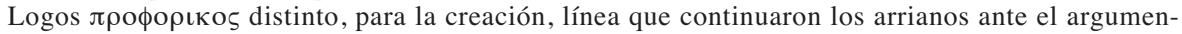
to de que Dios siempre tuvo Logos.

(42) Cf. p. e. Alejandro de Alejandría, Ep synod (Sócrates, Hist eccl, I, 6, 106); Atanasio, C. Arian, I, 5.32; De decretis, 6; Ep . ad epic Aeg et Lib, 12; De synodis, 18; 36.

(43) Así participa del Padre (cf. p. e. De decretis, 9).

(44) Así en De decretis, 8.

(45) Según Orígenes, el que el Espíritu sea o no engendrado no está claro en la tradición y es un problema para investigar (De princ, Prol, 4). Para Agustín es claro que no es hijo, pero la explicación de esto solo la conoceremos en el cielo (De Trin XV, 25 (45), 17-20; cf. Ib., V, 14 (15), 7-12; IX, 12 (18), 39-75; XV, 26 (47), 102ss; XV, 27 (50), 100-106, etc.).

(46) Cf 1Ser, 15; 4Ser, 1ss; Gregorio de Nacianzo, Orat, 31, 7s.

(47) Según A. De Halleux, esta expresión corresponde claramente al segundo miembro del artículo segundo ( $\varepsilon \kappa \tau o v \pi \alpha \tau \rho \circ \varsigma$ $\gamma \varepsilon v \nu \eta \theta \varepsilon v \tau \alpha$ ), sin que por eso deba implicar una definición precisa, en el sentido de Gregorio de Nacianzo, de la manera específica de ser del Espíritu. 'Padre' significa aquí, según la enseñanza trinitaria de los capadocios, la fuente o el principio de la divinidad. Un Filioque no correspondería ni a la intención del texto ni a la teología subyacente (La profession de la Esprit-Saint dans le symbole de Constantinople, RTL 10(1979)5-39, p. 33ss). 
cambiando $\pi \alpha \rho \alpha$ por $\varepsilon \kappa(48)$. Su traducción latina, 'proceder', la podemos aplicar tanto al Espíritu como al Hijo en la Trinidad (49). Que el Espíritu proceda del Padre es para afirmar su divinidad: no viene de la nada. Y queda en paralelismo con lo del

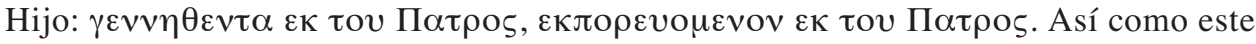
es engendrado, el Espíritu $\varepsilon \kappa \pi о \rho \varepsilon v \varepsilon \tau \alpha \iota$. Esta contraposición ya apropia al Espíritu

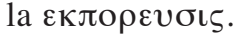

Cuando Basilio trate de caracterizar las personas divinas, dirá que lo propio del Espíritu es santificar (50). Esto es 'propio', pero pertenece a la economía y no está al nivel de la teología, como la relación Padre e Hijo. Entonces vendrá Gregorio de

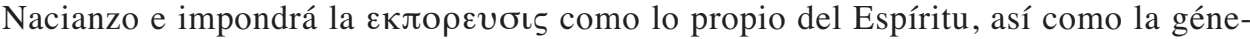
sis lo es del Hijo. Si los latinos solo apropian la 'processio' al Espíritu, se debe en parte a una sutil diferencia de lenguaje. Pero Atanasio, en una profunda vivencia trinitaria había prolongado la lucha contra los que niegan la divinidad del Hijo, a los que niegan la divinidad del Espíritu, porque lo que el Hijo es al Padre, el Espíritu es al Hijo, p. e. imagen (51). Luego negar la divinidad del Espíritu es volver a negar la del Hijo. La Trinidad no permite ninguna división (52). Atanasio, pues, siguiendo una antigua tradición, había recalcado mucho la intermediación del Hijo entre el Padre y el Espíritu (53). Entonces Gregorio de Nisa llegará a definir lo propio del Espíritu, como el proceder mediante el Hijo, lo que no obsta para la relación natural del Espíritu con el Padre (54). Y que el Espíritu proceda del Padre por el Hijo va a ser el sentir oriental en la época de los Padres. Y esta es la fórmula que usó el Vaticano II al tocar este tema (55).

Nos preguntamos entonces ¿por qué no quedó esto en el símbolo de Constantinopla I? Una primera razón podría ser no querer apartarse demasiado de la letra del texto bíblico, aunque, según este, todo lo del Padre sea del Hijo y el Espíritu tome de lo del Hijo (56), etc. Pero probablemente la razón principal fue no dar pie a una

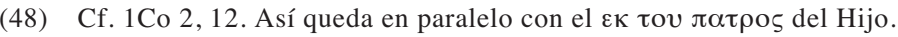

(49) Aunque apropiemos ‘procesión' al Espíritu, las procesiones en Dios son dos.

(50) Ep 214, 4; 236, 6. Véase Gregorio de Nacianzo, Orat 31, 4. Respecto a lo propio del Espíritu según los 3 Capadocios, véase Simonetti, La crisi, 515-518. Basilio insinuará también que es como el soplo de la boca de Dios (De Spir S, XVI, 38; XVIII, 46). Esto derivará en la relación voz y soplo, que leemos por ejemplo en Juan Damasceno De fide orth, 1, 7. Véase, p. e., Gregorio de Nisa, Orat catech, II.

(51) Cf. p. e. 1 Ser, 20; 24; 4 Ser, 3.

(52) Tampoco nada de lo creado puede entrar en la Trinidad, que es un solo Dios. Según F. Courth, "Wenn Athanasius solchermassen von der einen göttlichen Natur spricht, meint er nicht eine abstrakte Wesenheit Gottes; sondern er hat das ewige und untrennbare Ineinandersein von Vater, Sohn und Geist im Auge" (Trinität in der Schrift und Patristik (Handbuch der Dogmengeschichte, II, $1^{\text {a }}$, Herder 1988, p. 142). La mutua compenetración e inhabitación de los tres se manifiesta en fómulas como: "Porque el Padre todo lo hace a través del Hijo en el Espíritu Santo" (Ad Ser I, 28).

(53) Cf. p. e. 1Ser, passim. El Espíritu tiene respecto al Hijo el mismo orden y naturaleza que este tiene respecto al Padre (1 Ser, 21). Véase $I b ., 2 ; 21 ; 3 \mathrm{Ser}, 1 ; 3$.

(54) Quod non sint, GNO III, 1, 56, 4-10. Cf. C Eun, I, 280.378.533, GNO I, 108, 11-109, 5; 138, 915; 180, 27-181, 5. La explicación de Ricardo de San Victor, también tiene la intermediación del Hijo, porque el Hijo quiere que otro comparta el ser amado por el Padre (De Trin, III, 11). El Espíritu es el tercero, el condilecto (Ib., III, 19), que lleva a su plenitud el amor.

(55) $A G, 2$.

(56) Jn $16,14 \mathrm{~s}$. 
interpretación de 'por el Hijo' en el sentido de que todo fue creado por el Logos según Jn 1, 3, incluido el Espíritu. Agustín, asumiendo el consubstancial de Nicea, va a obviar esto declarando que, aunque procede principialmente (toma su origen) del Padre, procede en comunión (communiter), del Padre y del Hijo como de un solo principio (57). Porque el Padre dio todo al Hijo (salvo el ser Padre), aun espirar el Espíritu (58), como dirá el concilio de Florencia. El concilio de Contantinopla I dejó aquí un vacío, porque, como argumentará la Escolástica, si el Espíritu no procede del Hijo, no se le distingue (59). Para los occidentales y en latín (no en griego), la fórmula quedará: qui ex Patre Filioque procedit (60). Pero notemos que hay una sutil diferencia entre el 'proceder' latino (61) y la $\varepsilon \kappa \pi о \rho \varepsilon v \sigma \iota \varsigma$ griega.

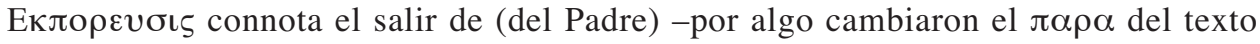
bíblico por $\varepsilon \kappa$. El procedere latino, en cambio, indica avanzar hacia (62). Por tanto, los latinos mantienen la única fuente, el Padre, pero con 'mediación' del Hijo en la comunicación de la divinidad al Espíritu. Según Máximo el Confesor, que en un pasaje (63) se hace eco de Roma, el Filioque no concierne la $\varepsilon \kappa \pi$ o $\varepsilon v \sigma ı \varsigma$ del Espíritu provenido del Padre en cuanto fuente de la Trinidad, sino que manifiesta su

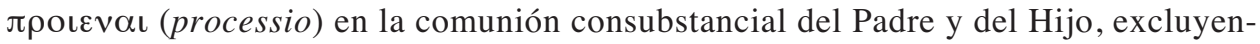
do una eventual interpretación subordinacionista de la monarquía del Padre. Esto correspondería a las imágenes de los apologistas: fuente, río y agua que bebemos; sol, rayo (resplandor), luz que nos ilumina (64). Bajo este aspecto estuvo bien la intuición del concilio de Florencia de que la fórmula latina equivalía a la oriental.

Ciertamente los latinos no ponemos dos fuentes, como declara el concilio de Lyon II. Tampoco es verdadera la objeción de Focio, que, según los occidentales, el Espíritu terminaría procediendo de sí mismo, dado que procede de la substancia divina con la que se identifica, porque para los occidentales el 'unico principio' de Agustín, no es la substancia divina sino el Padre y el Hijo en su común espirar (el Hijo lo recibe del Padre), porque como dice el concilio Lateranense IV ante la objeción de Joaquín de Fiore contra Pedro Lombardo, la substancia divina "ni engendra, ni es engendrada, ni procede, sino que es el Padre el que genera, el Hijo el que es engendrado y el Espíritu el que procede" (65). Finalmente el Constantinopolitano I dice que procede del Padre. Si es Padre, es porque tiene un Hijo. Luego el Credo implica de alguna manera, al menos en nuestra lectura, al Hijo en el que el Espíritu proceda del Padre. Podemos decir que el Padre no engendra al Hijo sin

(57) De Trin XV, 26 (47), 113-115; V, 14 (15), 32-35. Cf. Ib., V, 14 (15), 30-37; XV, 17 (29), 54-62; XV (45) 26, 9-18; XV (47), 26, 94-100, etc.

(58) Agustín, In Joh 99, 8, 9-12; De Trin XV, 27 (48), 16-18 (cf. Ib., 27, 30-32). Cf. De Trin IV, 20 (29), 102-123 (mostrando que el principio de toda la divinidad, o quizás mejor dicho, de toda la deidad, es el Padre); Ib., XV, 26 (47), 94-100; Contra Max II, 14, 1, etc.

(59) Porque no se oponen. En Dios omnia sunt unum, ubi non obviat relationis oppositio (DH $1330)$.

(60) Cf. S. Zañartu, El Espíritu y el Hijo en la fe de la Iglesia. Algunos alcances respecto a la controversia sobre el Filioque, Teología y Vida 40 (1999)278-311.

(61) En griego se podría significar con $\pi \rho 0 \iota \varepsilon v a l$.

(62) Mira a la comunicación de la única substancia divina.

(63) Véase Ep ad Marinum, PG 91, 136AB.

(64) Las retoma Atanasio, p. e., en 1Ser, 19.

(65) DH 804. 
espirar el Espíritu, y que el Hijo no nace del Padre sin que por Él pase la espiración. Dicho más técnicamente, la procesión del Espíritu sería como condición de posibilidad de la del Hijo. Gracias a la procesión del Espíritu, don del amor del Padre al Hijo, el Hijo alcanza su plenitud filial y el Padre su plenitud de paternidad: es la plenitud trinitaria (66). El Espíritu es el que lleva a la Trinidad a su consumación. De aquí que siempre veamos al Hijo y el Espíritu juntos (67).

Agustín fue el primero en apropiar el amor al Espíritu (68). Este es el amor mutuo entre el Padre y el Hijo, que fluye de ambos como de un solo principio, por así decirlo al modo de fruto, de amor procedido, de vínculo entre ambos. Esto ha sido representado a veces en un esquema triangular, que es coherente con el Filioque (69). Pero así como el concilio de Calcedonia (70) puede ser mal leído, si se interpreta el único $\pi \rho \circ \sigma \omega \pi$ ov o hipóstasis de Cristo como una persona que tiene dos naturalezas equivalentes respecto a sí misma, y no como la divina 'persona' del Logos que tomó carne (insistencia de Alejandría) por su poder creador, siendo su naturaleza humana creada (71); así también el amor mutuo entre el Padre y el Hijo puede ser mal entendido como 'dos fuentes' que amándose producen (espiran) el Espíritu, que se aman en el Espíritu, cuyo amor es el Espíritu que los vincula, olvidándose que el Hijo recibe del Padre el espirar el Espíritu. Es, por tanto, un amor mutuo, pero análogo en la mutualidad: el Padre engendrando y el Hijo siendo engendrado (72). La relación del Hijo con el Padre se refracta a distancia infinita (creatural) en el diálogo de Jesús con su Padre, p. e. en la obediencia del huerto. Así no se aminora la monarquía del Padre.

Volvamos al Credo del Constantinoplitano I. Hasta ahora hemos visto una sola forma de decir la divinidad del Espíritu: por la procedencia del Padre. Después de la experiencia del fuerte rechazo que produjo el ouoovoıs se Nicea por no estar en la Escritura (73), siguiendo la línea dialogante de Basilio

(66) Véase Les traditions grecque et latine concernant la procession du Saint Esprit. Clarification du Conseil pontifical pour la promotion de l'unité des chrétiens (Doc Cathol, 5 Nov 1995, pp. 941945), p. 944.

(67) Esto postula un equilibrio entre cristología y pneumatología.

(68) Y si la caridad con que el Padre ama al Hijo y el Hijo ama al Padre demuestra la inefable comunión de ambos, ¿qué cosa más conveniente que propiamente sea llamado caridad aquél que es el Espíritu común para ambos. (De Trin XV, 19 (37), 139-143). Cf. De Trin VI 5 (7), 16-19; De Trin XV, 17 (27), 2-5; XV, 17 (29), 66-72; XV, 17 (31), 96-134; XV, 27 (50), 87-89; In Joh 105, 3, 5-7; De Civ Dei, XI, 24, 13ss, etc.

En el N. T., o $\theta \varepsilon o \varsigma$ (el Padre) es amor (1Jn 4, 8.16; cf. 2Co 13, 13). Es el Padre que no reservó a su Hijo por amor al mundo (Rm, 8, 32; cf. Jn 3, 16; 1 Jn 4, 9s). Y el Espíritu es el que ha derramado ese amor en nuestros corazones (Rm 5, 5).

(69) Como que el esquema agustiniano se cerrara un poco sobre sí mismo (el triángulo se termina en sí mismo). Parece más dinámico, en cambio, el esquema oriental, en que el Espíritu procede del Padre por el Hijo. Porque en un salto infinito, el dinamismo de la línea puede seguir más allá hacia la creación. Dios sale en el Espíritu y nosotros volvemos a él en el Espíritu por el Hijo (cf. Ef 2,18). Esta concepción prenicena se presta más a la economía; en cambio el triángulo, que es coherente con el Filioque, es posniceno.

(70) Cf. S. Zañartu, Reflexiones sobre la fórmula dogmática del concilio de Calcedonia, Teología y Vida 39 (1998)155-184, p. 169s.

(71) El Logos es su naturaleza divina, y el que sea también humano se debe a una libre asunción en el tiempo, aunque para siempre.

(72) El Espíritu es amor como 'espiración’ del Padre por el Hijo.

(73) Los ortodoxos harán notar que el $\alpha \gamma \varepsilon v \vee \eta \tau o \varsigma$ de Eunomio tampoco estaba en la Escritura. 
(74), no solo lo evita el concilio respecto al Espíritu, sino también evita llamarlo directamente Dios (75), porque tampoco está en la Escritura. Esta ausencia era gran argumento de los pneumatómacos contra la divinidad del Espíritu. Yo diría que no se lo llama Dios porque es el Espíritu de Dios. Y, según Atanasio (76), por estas determinaciones se distingue el Espíritu Santo de los otros espíritus. Aquí reencontramos el problema de lo poco que se habla en la Escritura de la distinción del Espíritu respecto a Dios. Espíritu de Dios (su fuerza) implica que le está íntimamente unido; Espíritu Santo, expresión que entra fuertemente en el Nuevo Testamento (77), implica que comparte la santidad de Dios y que santifica en referencia a la

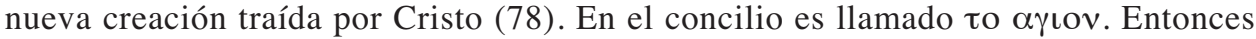
el Credo dirá que es Dios con expresiones que lo impliquen, como también ya vimos que era el que proceda del Padre (79).

(74) Este, en su De Spiritu Sancto probando de múltiples formas que el Espíritu era Dios ( $\tau$ o $\theta \varepsilon \iota 0 \vee \tau \eta$, $\phi \cup \sigma \varepsilon \iota$, según XXIII, 54, 17), no lo afirmó explícitamente, porque no estaba en la Escritura. Gregorio de Nacianzo Orat 43, 68s; Ep 58, 5ss) nos da el testimonio sobre su creencia personal al respecto. Véase Idem, Orat 41, 6. Según A. Meredith (The Pneumatology of the Cappadocian Fathers and the Creed of Constantinople, IThQ 48 (1981)196-211, p. 205), "On the contrary the defective nature of his pneumatology proceeds from an imperfect (or barely existent), awareness of the role played by the Holy Spirit in the work of creation". Atanasio en 1 Ser, 27, le aplica ouoovotos.

(75) A. de Halleux (La profession, p. 38) llega a expresar el siguiente juicio bastante crítico respecto a lo que se dice del Espíritu, que parecería un poco de compromiso: "Car s'il est bien exact que la divinité de la troisième personne trinitaire se trouve équivalemment indiquée par des attributs "saint, seigneur et créateur de vie, sortant du Père"- incompatibles avec la condition de créature, il reste qu'aucune de ces qualités, non plus que l'association de l'Esprit à l'adoration et à la glorification du Père et du Fils, n'implique nécesairement la parfaite consubstantialité. Tout en excluant ceux des pneumatomaques qui refusaient la divinité de l'Esprit, la profession de foi demeurait donc acceptable pour ceux qui auraient interprété cette divinité à la manière homéousienne, c'est-à dire comme non numériquement identique, mais seulement égale, ou même semblable, à l'essence du Père et du Fils... Charte d'une union avortée avec les 'pneumatomaques', inférieur en cela à sa destinée de profession liturgique de la foi universelle, le symbole de Constantinople a mis en sourdine la divinité de l'Esprit qu'il entendait pourtant défendre, tu son économie par crainte qu'il en fût abusé, et préparé, par une ambigüité bien involontaire, le schisme entre les deux parties de la chrétienté". Puede verse A. M. Ritter, Das Konzil von Konstantinopel und sein Symbol. Studien zur Geschichte und Theologie des II. Ökumenischen Konzils (Forschungen zur Kirchen- und Dogmengeschichte, 15), Göttingen 1965, pp. 195-197.

(76) Cf. 1Ser, 3-8.

(77) En el A. T. hebreo solo se habla dos veces de Espíritu de santidad (Is 63, 10s; Sal 51, 13). Los LXX hablarán de Espíritu Santo también en Dn 5, 12; 6, 4; Sb 1, 5; 7, 22; 9, 17.

(78) Según Jn 7, 39, el Espíritu no había sido dado a nosotros porque Jesús no había sido glorificado. Según Tomás, la misión visible del Espíritu como signo de santificación, tiene que ser precedida de la misión de Jesús, autor de la gracia.

(79) El proceder del Espíritu en el Credo tiene un tinte económico (cf. J. Wolinski, La pneumatologie des Pères Grecs avant le Concile de Constantinople I, p. 160s, en Credo in Spiritum Sanctum...., pp. 127-162): es el Espíritu vivificante, que habló por los profetas, que es coadorado y conglorificado; es el que interviene en la Encarnación de María virgen. Reafirma implícitamente que es un solo Espíritu: del viejo y nuevo Testamento, y de los cristianos. Halleux afirma respecto al Espíritu que habló por los profetas: "Il est plus malaisé de préciser l'intention de la clausule dans le constantinopolitanum. Si le modèle était semblable au symbole de Jérusalem, les rédacteurs en auraient abandonné la préposition 'dans' pour retrouver le 'par' de Justin et d'Irénée, peut-être en un simple correction de style. Réaffirmèrent-ils le prophetisme de l'Ancienne Alliance parce qu'ils voyaient dans la sainteté des divines Écritures une preuve supplémentaire de la divinité de l'Esprit-Saint qui les avait inspirées? Il est frappant, en tous cas, que les profesiones synodales arianisantes, derivées du symbole 'lucianique' d'Antioche, développent complaisamment l'économie pentecostale du Paraclet sans souffler mot de l'inspiration prophétique vétéro-testa- 


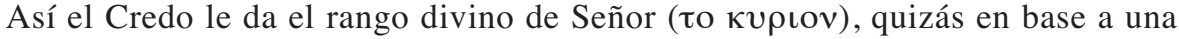

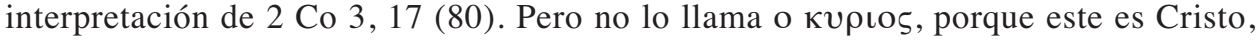
el único Señor, como ha dicho Nicea y repite ahora Constantinopla I. Es vivificante

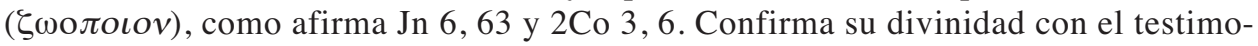
nio litúrgico del culto cristiano: es coadorado (81) y conglorificado con el Padre y el Hijo (82). La conglorificación la encontramos, p. e. en 1 ad Serapionem de Atanasio (83), junto con una serie de otros argumentos, entre los que destaco que el Espíritu nos diviniza (84). El De Espiritu Sancto de Basilio había defendido la doxología "gloria al Padre con el Hijo y con el Espíritu Santo" (85) contra Eustacio de Sebaste entre otros, que solo querían la antigua "gloria al Padre por el Hijo en el Espíritu".

\section{RESPECTO A LA FÓRMULA TRINITARIA}

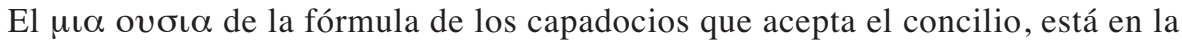
línea del opoovoıos de Nicea contra los arrianos, explicitando la unidad numérica. Según cuenta Atanasio, los arrianos en Nicea estaban dispuestos a aceptar las otras formulaciones sobre el Hijo porque las podían interpretar a su manera, pero no el

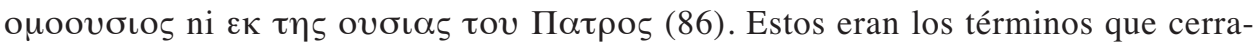
ban el paso a su doctrina, aunque Eusebio de Cesarea haya intentado después interpretarlas a su modo explicando a su comunidad el haber firmado (87). Que viniera

mentaire: celle-ci aurait-elle paru contredire la soumission de l'Esprit au Christ, que son envoi par le Ressuscité voulait suggérer? Les Pères de Constantinople auraient alors trouvé dans la clausule prophétique de leur modèle un excellent antidote contre le subordinationisme pneumatomaque, quitte à omettre toute mention du Paraclet" (La profession, 31). A lo que añade B. Pottier: "L'habilité des Pères conciliaires consista donc à ne parler que de l'Esprit déjà à l'oeuvre dans l'A. T., avant l'incarnation du Verbe donc, ce qui mettait et le Verbe et l'Esprit dans une préexistence commune assurant leur homotimie" (Dieu et le Christ selon Grégoire de Nysse. Etude systématique du 'Contre Eunome' avec traduction inédite des extraits d'Eunome, Namur 1994, p. 370).

(80) Cf. Basilio, De Spir S, XXI, 52; Kelly, Primitivos Credos, 404-408.

(81) Cf. p. e. Basilio, Ep 90, 2; Gregorio de Nacianzo, Orat 31, 12.28.33. Sobre estos atributos que indican la divinidad del Espíritu, puede verse I. Ortiz de Urbina, Nicée et Constantinople (G. Dumeige, Histoire des Conciles Oecuméniques, 1), Paris 1963, pp. 193-205.

(82) Véase p. e., Cirilo de Jerusalén, Catech, XVI, 4.

(83) Núm. 31. Cf. Basilio, Ep 159, 2.

(84) Núm. 24 y 25. Respecto a los testimonios de la Escritura sobre la divinidad del Espíritu, véase también por ejemplo, Gregorio de Nacianzo, Orat 31, 29.

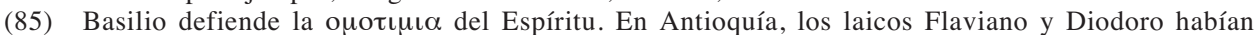
modificado la antigua doxología "Gloria al Padre por el Hijo en el Espíritu Santo" en "Gloria al Padre y al Hijo y al Espíritu Santo", para evitar el peligro de una interpretación subordinante (Simonetti, La crisi, p. 361 n. 24).

(86) De decretis, 19s; De synodis, 45; Ep ad afros, 5s. Las otras también las podían decir de nosotros, p. e., el venir de Dios, ser hijos de Dios o la semejanza. Sobre el significado del símbolo, puede verse, Kelly, Credos, pp. 281 ss.

(87) Según él, Constantino aclaró que ouoovoıos no significaba división ni escisión, como acontece en la naturaleza corpórea (Ep Eusebii, 7). En el mismo sentido, en la discusión le aclararon a Eusebio que 'de la substancia del Padre' no quiere decir que el Hijo exista como parte del Padre $(I b ., 9)$. Aceptó igualmente 'no hecho', porque decían que 'hecho' ( $\pi$ oı $\eta \varepsilon \varepsilon v$ ) era un término común con el resto de las creaturas hechas por el Hijo, con las que nada tiene de semejante el Hijo (Ib., 11). Consubstancial significa, pues, que el Hijo no tiene ninguna semejanza con las 
de la substancia del Padre (alternativa a venir de la nada), los arrianos lo veían como una escisión de substancia. Por esa misma razón, esta expresión no gustaría a Orígenes (88). Pero este segundo inciso terminó desapareciendo en el Credo del Constantinopolitano I.

La pelea por el ouoovoıs (89) va a ser grande y durará al menos hasta el Constantinopolitano. Este vocablo (90), que ya encontramos en la descripción del valentinismo gnóstico en Ireneo (91), había sido condenado, en torno a Pablo de Samosata el año 268 (92). Por esa misma época, Dionisio de Alejandría afirma no haberlo usado por no ser bíblico, pero decir lo equivalente con otras expresiones (93).

creaturas hechas sino que en todo es semejante al Padre que lo ha generado y no (viene) de alguna otra hipóstasis y ovoı $\alpha$ sino del Padre $(I b ., 13)$. Repecto a "de la nada" y "hubo un tiempo...", fue prohibido su uso por no estar en la Escritura, lo que suele provocar desorden y confusión. El emperador era de este parecer $(I b ., 15)$. Anatematizar que no existiera antes de ser generado, no le pareció fuera de lugar, porque existía antes del nacimiento según la carne. Constantino declaró, según el relato de Eusebio, que su nacimiento divino es anterior a todos los siglos, porque antes de ser generado en acto existía en potencia en el Padre sin generación ( $\alpha \gamma \varepsilon v \nu \eta \tau \omega \varsigma)$ (porque el Padre siempre fue Padre), como todas las cosas en potencia (Ib., 16). Así se disculpó Eusebio por haber firmado Nicea. Sobre la posible propuesta de su símbolo baustimal al Concilio para librarse de las sospechas al haber sido momentáneamente condenado en el del todo reciente concilio de Antioquia por su apoyo a Arrio, véase Simonetti ( a crisi, 83s), quien cree que más bien sería para evitar una precisa toma de posición antiarriana de parte del concilio. Los obispos que no firmaran fueron amenazados con el destierro. Cf. Kelly, Primitivos Credos, cap. 7.

(88) Cf. In Ioan, 20, 18, 157-159. Según Simonetti (La crisi, 12), “per formulare l'unione delle ipostasi nell'unica divinità, Origene rifugge dal parlare di sostanza, sostrato comune (=spirito) ad esse, perchè ravvisa in questo concetto una precisa connotazione materialista d'origine stoica, un sostrato materiale che si divide in più parti". Cf. Courth, op. cit, 100s. Sobre su uso, puede verse, p. e., I. Ortiz de Urbina, El símbolo niceno, Madrid 1947, 137s. Cf. R. Lorenz, Arius judaizans? Untersuchungen zur dogmengeschichtlichen Einordnung des Arius (Forschungen zur Kirchenund Dogmengeschichte, 31), Göttingen 1980, 72-76.

(89) Cf. p. e. Kelly, Primitivos Credos, 290 ss.

(90) Respecto al vocablo y al concepto, puede verse, G. Stead, Homoousios, RAC, XVI, col. $364-433$. "The original signification of homoousios, apart from all theological technicality, is simply "made of the same stuff'. 'Stuff' here bears a generic sense, necessarily, since no objects of physical experience are composed of identical portions of matter; it really means 'kind of stuff'” (Prestige, op. cit., 197). Puede también verse la posición crítica de Stead a afirmaciones de Prestige en The Significance of the homoousios, Studia Patristica 3 (Oxford 1959), 397-412.

(91) Adv Haer, I, 5, 1; I, 5, 6, etc.

(92) Según Hilario (De synodis, 81), habría sido usado por Pablo en forma modalista; según Atanasio (De synodis, 45; cf. Basilio, Ep 52,1), supondría una substancia anterior que se divide en dos (Padre e Hijo), quienes serían opoovoıo . Véase la interpretación de P. de Navascués, Pablo de Samosata y sus adversarios. Estudio histórico-teológico del cristianismo antioqueno en el s. III (Studia Ephemeridis Augustinianum, 87), Roma 2004, pp. 437-453. En p. 444 afirma este autor: "Más de un autor concuerda en señalar que el sentido más común a homousios en época prenicena es el de subrayar una unidad genérica, no tanto numérica, entendiendo ousia no tanto como natura (physis) ni como persona (hypostasis) sino más bien como sustrato, sustancia de la que se origina el ser homoousios, por emanación, corte, división, en suma, por un fenómeno propio de los cuerpos". Por algo Constantino, según Eusebio como vimos antes, tendría que aclarar que ouoovoros no significaba división ni escisión, como acontece en la naturaleza corpórea. Los homeousianos llamaron la atención sobre esta condenación en el concilio de Ancira de 358.

(93) Cf. Atanasio, De sent Dion, 18; De decretis, 25; De synodis, 44. Según Dionisio, los padres solo difieren de los hijos por no ser ellos los hijos. Como la planta difiere de la raíz, pero le es del

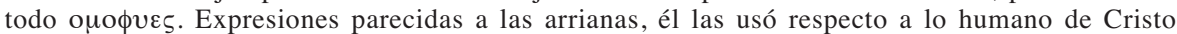
para así mostrarlo como distinto del Padre contra los sabelianos (cf. De sent Dion, 4-5; 12; 19; 26). Sobre Alejandro de Alejandría afirma Simonetti (La crisi, p. 29 n. 8): "Alessandro non parla mai, nei suoi testi a noi pervenuti, di consustanzialità del Padre e del Figlio perchè il termine e il concetto erano estranei alla sua dottrina trinitaria". Estaba muy ligado a la tradición origenista. 
Antes de Nicea también había sido rechazado por Arrio (94). Triunfó en Nicea con el respaldo de Constantino (95), probablemente bajo la influencia de Osio de Córdoba. Lo apoyarían los obispos de tendencia monarquiana como Eustacio de Antioquía. Y pudo ser aceptado por origenistas moderados, como Alejandro de Alejandría, para combatir a Arrio. Pero otros lo percibirán como modalista (96). Y un gran defensor de Nicea era justamente Marcelo de Ancira que aparecerá condenado por su modalismo en el canon 1 del Constantinopolitano I, y a propósito del cual se añadirá al Credo que el reino de Cristo no tiene fin (97). Los occidentales, de tendencia más bien monarquiana, no tuvieron sensibilidad para detectar la herejía en Marcelo (98), y así lo absolverán en el concilio de Roma del 341 y en el de Sárdica del 343. Condenarán, sí, a su discípulo Fotino, pero este además era tenido por adopcionista. La dificultad de Nicea, concilio tan fundamental para la doctrina de la fe, fue haber sido unilateral, condenando un extremo (subordinacionismo) y no el otro (modalismo, sabelianismo).

¿Qué quisieron decir con opoovoıs en Nicea? Por el contexto inmediato, que el Hijo era igualmente Dios como el Padre, generado de su substancia; que era Dios verdadero de Dios verdadero; que no era creatura como afirmaba Arrio. Pero, más allá de esto, cada uno lo entendería a su manera (99). Por ejemplo, los hombres también somos consubstanciales (pertenecemos al mismo género o especie) y así, por ejemplo, el acta de unión del 433 y Calcedonia dirán de Cristo que es consubstancial al Padre y a nosotros (100). Con todo, respecto al Padre la consubstancialidad es numéricamente una (la substancia divina es única, aunque sea común a los tres), pero respecto a nosotros es específica (nosotros somos diversas substancias individuales de la misma esencia humana). Aunque algunos no lo hubieren entendido así en el momento de Nicea (101), si analizamos el Credo de Nicea, el consubstancial implicaría la unidad numérica (102, porque depende del 'un ( $\varepsilon v \alpha)$ Dios', que

(94) En Thalía y en carta a Alejandro (Atanasio, De synodis, 15 y 16).

(95) Cf. Ep Eusebii, 7 (cf. 13).

(96) El mismo Basilio de Cesarea, según Simonetti (La crisi, 412), creerá que los paulinistas de Antioquía, nicenos estrictos que serán apoyados por Roma y Atanasio, eran modalistas. Cf. Basilio, ep 263, 5; 214, 3; 236, 6. Véase Hanson, op. cit., p. 801s. Los posteriores luciferianos serán acusados de sabelianismo (cf. Simonetti, La crisi, p. 445 n. 34). Según Prestige (op. cit., 212), "The charge against it (ouoovoเos), that it countenanced Sabellianism, was not raised until Marcellus wrote a defense of it which could colourably be said to be Sabellian".

(97) Esto desde hace algún tiempo eran introducido en los Credos y el mismo Marcelo había desistido de su afirmación contraria.

(98) J. T. Lienhard (Contra Marcellum. Marcellus of Ancyra and Fourth-Century Theology, Washington 1999, p. 137), quien no atribuye a Marcelo De sancta Ecclesia, opina: "Later documents show that he corrected his theology and brought it more and more into line with miahypostatic orthodoxy. Marcellus abandoned his insistence that the Preincarnate is properly only Word, and that Christ's reign will end, but held on to his belief in the eternity of the Son-Word and his full divinity, and particularly to the expression "one hypostasis"".

(99) Ya vimos la interpretación de Eusebio de Cesarea. "Il consenso finale dovette essere per conseguenza piuttosto generico, in quanto con homooúsios si intese puntualizzare soltanto la natura autenticamente divina del Figlio come quella del Padre" (A. Milano (Persona in teologia. Alle origini del significato di persona nel cristianesimo antico (Saggi e Ricerche, 1), Napoli 1984, p. 117).

(100) Esta doble consubstancialidad de Cristo ya había aparecido en las expresiones de Dionisio de Alejandría (cf. Atanasio, De sent Dion, 10 y 18-20).

(101) Cf. J. N. Kelly, Early Christian Doctrines, London 1980, 5ª ed., pp, 233-237.

(102) Cf. I. Ortiz de Urbina, El símbolo, 178-216; Id., Nicée, 85s. 
es el Padre (103), confesado al comienzo. Y a eso añade, siguiendo el esquema 'monárquico' paulino (104), un solo Señor, engendrado por Dios y que le es consubstancial. Pero esta consubstancialidad numérica, como decimos nosotros, es en la substancia, que es común a ambos. Si fuera en la persona (del Padre), caeríamos en el modalismo que temían los adversarios. Estos se podrían ver confirmados en su interpretación modalista, según Simonetti (105), por el anatematismo final añadido al Credo contra los que dicen que es de otra hipóstasis o ovoı (106), es decir contra los que dicen que es creatura. Porque hipóstasis, aunque fuera un término no bien definido tenía más sabor al subsistente particular, a connotar la 'persona' del

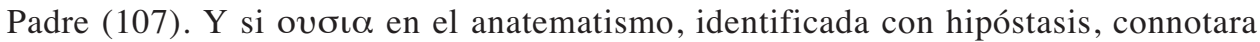
persona, ¿por qué no en el ouoovoıos del Credo? (108). Dejando a un lado esto último, ciertamente la forma de expresarse equivaliendo ovoı $\alpha$ con hipóstasis, tendía a excluir las 3 hipóstasis en Dios (109), de las que hablaban los origenistas.

El temor al modalismo se acentuará por la actuación de Marcelo de Ancira, gran defensor de Nicea. Lo anterior, más la deposición de Eustacio y otros nicenos,

(103) El Credo no dice: creo en un solo Dios, que es Padre e Hijo y Espíritu Santo (cf. Ortiz de Urbina, Nicée, 73-76).

(104) Cf. p. e. 1Co 8, 6. Véase 1Co 12, 4-6; Ef 4, 4-6; Jn 17, 3.

(105) La crisi, 94, et passim.

(106) Cf. C. Stead, Divine Substance, Oxford 1977, 233-242. "Les Pères de 325 avaient peut-être simplement voulu exclure une cosmogonie dualiste posant comme substrat de la création un principe matériel coéternel au Démiurge" (A. de Halleux, La réception du symbole oecuménique, de Nicée à Chalcédoine, p. 33, en idem, Patrologie et oecuménisme, 25-67). Respecto a una equivalencia de estos dos términos expresa Prestige (op. cit., p. 167s): "The 'substance' of God means the divine 'content', whether the actual term employed is ousia or hypostasis. To the mind of the Fathers, down to the time at which the terminology became fixed and technical, the practical meaning of the two terms was substantially identical" Pero más adelante dirá: "But ousia tends to regard internal characteristics and relations, or metaphysical reality; while hypostasis regularly emphasises the externally concrete character of the substance, or empirical objectivity. Hence, with regard to the Trinity, it never sounded unnatural to assert three hypostaseis, but it was always unnatural to proclaim three ousiai; although some writers, as will appear hereafter, occasionally use ousia in a sense approximating to that of hypostasis, definite examples of the reverse process are not often to be found" $(I b ., 188)$.

(107) En el Tomus ad Antiochenos, 6, firmado por Atanasio, se reconoce que decir "una hipóstasis" se

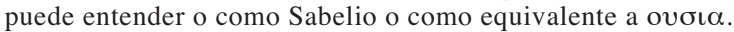

(108) Así, sobre los posteriores homeousianos, dirá Simonetti (La crisi, 261): "La rigida identificazione fra ousia e hypostasis impediva agli omeousiani di accettare l'homousion". "Gli omeousiani d'altra parte continuano la dottrina delle tre ipostasi e identificano ancora ousia con ipostasi, nel senso di sostanza individuale, ammettendo nella Trinità come tre ipostasi, così anche tre ousie" (M. Simonetti, Il Cristo. II: Testi teologici e spirituali in lingua greca dal IV al VII secolo, Fondazione Lorenzo Valla, 2a ed., 1990, II, p. 159). Basilio interpreta este anatematismo como disyuntivo: condena, por una parte, a los que niegan que sea de la ousia del Padre; y, por otra parte, a los que afirman que es de otra hipóstasis $(E p 125,1)$.

(109) Según Ritter (Das Konzil, p. 277, n. 2), "nach den nikäischen Anathematismen hingegen war es zumindest nicht ausdrücklich verboten, mit der origenistischen Tradition zu sagen, der Sohn sei oder habe eine andere Hypostase als der Vater. Ausdrücklich verboten wurde nur die Aussage, er sei aus einer anderen 'Hypostase oder Usie' als der des Vaters”. Opina Milano (op. cit., 117s): "Risultando condannata la specifica posizione ariana, a Nicea fu implicitamente anche accantonata la formulazione che insisteva sulle tre hypóstaseis distinte nella Trinità e dunque la dottrina origeniana che da quasi un secolo era tradizionale nella scuola alessandrina, ma che godeva larghi consensi in buona parte dell'episcopato orientale. In questa prospettiva il risultato del concilio di Nicea potrebbe essere visto come una vittoria momentanea della impostazione teologica monarchiana contro le divisioni che indebolivano i seguaci della dottrina delle tre hypostáseis". 
la forma autoritaria de actuar del controvertido Atanasio, la posición del cultísimo Eusebio de Cesarea, las intrigas de Eusebio de Nicomedia, de los melecianos y otros, la actitud de los emperadores filoarrianos de Oriente y su persecución, contribuyeron, entre otros factores, a la conformación de un frente amplio contra Nicea, excluidas las máximas exageraciones de Arrio (110), como calificar al Hijo creatura y desemejante. Este frente común, añadida la animadversión contra la intervención romana, perdurará hasta que se rompa en su interior con el neoarrianismo de Aecio y Eunomio, quienes volverán a afirmar del Hijo el ser creatura y desemejante en la substancia. Entonces, contra estos anomeos (111), reaccionarán muchos afirmando la semejanza según la substancia (opotovoıos) (112), capitaneados por Basilio de Ancira. Pero en un horizonte ya establecidamente antimodalista, que profesaba las tres hipóstasis, no era difícil que muchos se pasaran al ouoovoıos de Nicea (113), que ya no se prestaba a modalismo, como de hecho sucedió, gracias en parte al trabajo de Basilio de Cesarea (114), continuado por Gregorio de Nacianzo y Gregorio de Nisa (115). Así se produce el concilio de Constantinopla I. Es de notar cómo

(110) El emperador Constantino se va a empeñar en la rehabilitación de la persona de Arrio, pero no de su doctrina. El credo de Nicea, para él, era intangible. Por eso, hasta su muerte el 337, hubo persecución de nicenos, pero no substitución de su símbolo.

(111) Y contra la fórmula de Sirmio del 357

(112) Así resume Simonetti la confrontación de vocablos, a propósito de la intervención de Basilio de Cesarea: "gli omeousiani continuavano a propugnare la dottrina origeniana delle tre ipostasi trinitarie e facevano corrispondere alle tre ipostasi tre ousie distinte, in quanto assumevano ousia nel senso, prevalente nella tradizione alessandrina, di sostanza individuale... Atanasio invece, sulla traccia dell'homoousios niceno, preferiva parlare di ousia indifferenziata del Padre e del Figlio (e perciò anche dello Spirito santo), mentre si asteneva dal far uso, in contesti trinitari, del termine hypostasis; infine i niceni di vecchia osservanza affermavano una sola ousia e una sola ipostasi della Trinità. Essi consideravano triteisti gli omeousiani e, a loro volta, ne erano considerati monarchiani" (Il Cristo, II, 276).

(113) La profesión de fe de los Occidentales escrita en Sárdica no lo mencionaba, aunque sostenía una hypóstasis (o ovoı $\alpha$ ) de la divinidad. En torno al 355, "Atanasio, dopo un silenzio trentennale, ripropone l'homoousios niceno come stendardo dell'ortodossia antiariana" (Simonetti, Il Cristo, II, 152). Ya antes había afirmado X. Le Bachelet sobre Atanasio: "A part les ouvrages polémiques où il le défend contre les attaques des ariens et des semiariens, il se sert peu de l'ouoovoıos, à tel point que, dans les trois premiers discours contre les ariens, ce terme ne paraît

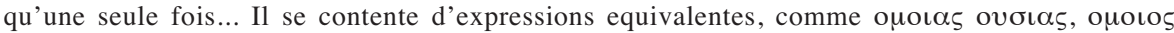

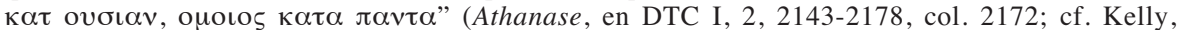
Doctrines, 245s). Respecto al cambio de Atanasio, expresa Th. A. Kopecek (A History of NeoArianism, I (Patristic Monograph Series, 8), Cambridge MA, 1979, 224s) "By means of his statement in De Synodis 53 Athanasius was seeking to put the Homoiousians on guard against the Neo-Arian dialectical subtlety. Homoiousion not only did not exclude Neo-Arianism but logically might be construed actually to imply it; the confession of homoousion was the only effective polemic against the essencial difference of God and the Son. The extent of Athanasius' fear of the Neo-Arians' dialectical threat to the Homoiousians was demonstrated by his devoting three entire sections of his De Synodis to arguing that homoousion alone logically refuted the position that God and the Son are one in will but not in essence (\# 48-50). And he added a section designed to prove that only homoousion could protect the Christian's hope of deification... Athanasius was gently insistent that homoiousion was a terminological muddle which in the end implied difference-in-essence. Christians had to choose between homoousion and heteroousion, between Athanasius und Aetius".

(114) Cf. B. Sesboüé, Saint Basile et la Trinité. Un acte théologique au IVe siècle. Le rôle de Basile de Césarée dans l'élaboration de la doctrine et du langage trinitaires, Ed. Desclée 1998.

(115) Ambos tuvieron que defenderse de la acusación de triteísmo (Cf. p. e. Gregorio de Nacianzo, Orat 31, 13; Gregorio de Nisa, S Trin, 5 (GNO III, 1); Com Not, 19 (GNO III, 1); Quod non sint, 38 (GNO III, 1)). 
los extremos causan reacción: primero Arrio, después el posible modalismo, y finalmente, el neoarrianismo de Eunomio.

En la época de predominio del arrianismo, por voluntad imperial, se llegó a extremos como el concilio de Sirmio del 357. Pasó a ser "prohibido" el uso del no

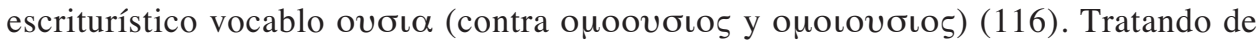
encontrar una línea media, que unificara el Imperio, el concilio de Constantinopla del 360, bajo el emperador Valente filoarriano, impone el simple ouoıos según las Escrituras como fórmula común (117). Los que se adhieren a esta fórmula aparecerán condenados en el canon del Constantinopolitano I, bajo el nombre de arrianos, con Eudoxio de Constantinopla a la cabeza (118). Pero, como ya en parte acabamos de ver, hubo una serie de obispos que no hablaba de solo semejanza sino de semejanza en todo, coincidiendo con el ouoovoıos, salvo en el vocabulario. Justamente, como ya vimos, lo que Hilario pretendió mostrar a los nicenos occidentales, es la coincidencia en el fondo, aunque no sea en el vocabulario entre Nicea y los que sostenían la semejanza en todo, incluyendo según la substancia. Eran dos formas de expresar lo mismo, con sus respectivos peligros (119).

Hasta aquí algo de la historia del ouoovoıos, que muestra cómo un término más filosófico vino ayudar a la expresión del dogma, terminando con la escala descendente platónica (120) o con el Logos intramundano estoico (121). Bajo este aspecto no se

(116) En su fórmula el Hijo ni siquiera es llamado 'semejante' respecto del Padre (cf. Hilario, De synodis, 11; Atanasio, De Synodis, 28). En Rimini en el 359 (igualmente a los de Seleucia) se termina imponiendo "semejante según las Escrituras" y se suprime ovoıd (Jerónimo, C Lucifer, 18). El concilio de Constantinopla del 360 prohíbe el uso de ovoı $\alpha$ y de hipóstasis (cf. Atanasio, De synodis, 30).

(117) Son los homeos, diferentes de los homousianos (Nicea) y de los homeousianos de Basilio de Ancira. "Acacio di Cesarea, che capeggiò questo grupo (homeos), propose infatti la formula che definiva il Figlio simile in tutto al Padre, formula -nonostante 1" "in tutto"- sufficientemente generica per poter essere interpretata in modi diversi, dall'ariano radicale fino all'omeousiano"(Simonetti, Il Cristo, II, 242).

A primera vista podía parecer una total victoria del emperador Constancio en Oriente: una fórmula común y exilio de Atanasio, que perturbaba la paz. Según la Exposición de la fe de Eunomio (núm. 3), es semejante como hijo, "en cuanto es imagen e impronta de toda la actividad y potencia del Todopoderoso, impronta de las obras, de las palabras y quereres del Padre".

(118) Por supuesto que el Hijo es semejante al Padre (es su imagen), pero profesarlo en esa época equivalía a querer negar el ouoovoıs. "Semejante" incluye una distinción antisabeliana. En ese canon también fueron condenados los eunomianos o anomeos (arrianos radicales).

(119) Cf. Hilario, De synodis, p. e. $67 \mathrm{ss}$.

(120) Fr. Ricken (Nikaia als Krisis des altchristlichen Platonismus, ThPh 44(1969)321-341, p. 340s) concluye así: "Das Homoousios von Nikaia ist nur von der mit dem Arianismus aufgeworfenen Fragestellung her zu verstehen. Im Arianismus verabsolutiert sich ein mittelplatonisches Denkschema, das seit den Apologeten im Anschluss an neutestamentliche Aussagen zur Deutung des Vater-Sohn-Verhältnisses herangezogen wurde. Das kosmologische Logosverständnis führt, unter dem Einfluss des christlichen Schöpfungsdenkens und des mittelplatonischen Streites um die Enstehung der Welt dazu, den Sohn dem Geshaffenen zuzuweisen. Der Arianismus stellt insofern eine erste Krisis des mittelplatonischen Denkens dar, als er heraustellt, dass es für den christlichen Glauben keine Stufung des Göttlichen und damit kein Drittes zwischen Transzendenz und geschaffener Welt gibt. Darin geht Nikaia mit Areios einig. Aber es korrigiert, von den Sohnesaussagen der Schrift herkommend, die Stellung des Logos. Homoousios heisst: Der Sohn steht auf der Seinstufe des transzendenten Gottes. Was wir vom transzendenten Gott aussagen, müssen wir auch vom Sohn aussagen. Nikaia bricht mit der naiven Rezeption des spätantiken Seinsverständnisses zur Deutung des christlichen Kerygmas. In diesem Sinne ist es das Ende des Zeitalters der Apologeten. Der Einschnitt des Jahres 325 hat bewirkt, dass die nachnizänische Theologie das triadische System Plotins, in dem der Mittelplatonismus aufgehoben ist, nicht als geeignet zur 
helenizaba la fe, sino todo lo contrario. Pero, en la fórmula, además de la única ovoı $\alpha$,

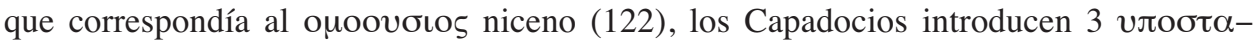

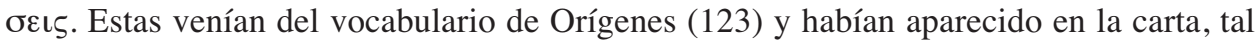
como la poseemos, de Dionisio de Roma respecto a lo que se decía en Alejandría en ese tiempo (124). A esto se interpuso el lenguaje de Nicea, que identificó hipóstasis con la ovoı $\alpha$ que era una. El trabajo de Basilio de Cesarea fue diferenciarlas (125): la única

Interpretation der trinitarischen Aussagen ansah". Puede verse también del mismo autor, Zur Rezeption der platonischen Ontologie bei Eusebios von Kaisareia, Areios und Athanasios, ThPh 53(1978)321-352.

(121) Según E. P. Meijering (Orthodoxy and Platonism in Athanasius Synthesis or Antithesis?, Leiden 1974 , p. e. en p. 126ss), el opoovoıos no solo niega la jerarquía descendente del platonismo, sino también el que Dios esté más allá de la ovoı́

(122) Puede verse la refutación de Ritter (Das Konzil, 270-293) de la tesis de Zahn, según el cual el opoovoıs de Nicea se refiriría a la única ovoı divina, mientras que en el Credo de Constantinopla I equivaldría al opoıoovoıos (Wesensgleichheit oder Gleichartigkeit der trinitarischen Personen). Termina afirmando Ritter: Denn trotz der bemerkenswerten terminologischen Unterschiede zwischen der kappadokischen und der durch Athanasios verkörperten sogenannten 'altnizänischen' Theologie ist das nikäische Homousios von den Kappadokiern und ihren Anhängern auf dem Konzil von Konstantinopel allem Anschein nach nicht anders verstanden worden als von Athanasios, nämlich als Ausdruck der numerischen Einheit der konkreten göttlichen Usie, des Seins Gottes selbst (ib. 292s).

(123) Nosotros creemos que hay tres hypóstasis: el Padre, el Hijo y el Espíritu Santo (In Joan II, 10, 75). Cf. In Joan X, 37, 246; C Cels VIII, 12. El fragmento 572 de In Mt (GCS 41, 1 (Origenes, 12), p. 235) dice: Es uno, no por fusión de los tres, sino por una esencia (ovoı $\left.)_{\iota}\right)$. Pero tres hypóstasis perfectas en todo y en mutua relación ( $\kappa \alpha \tau \alpha \lambda \lambda \eta \lambda o \iota)$. Según la naturaleza el Padre

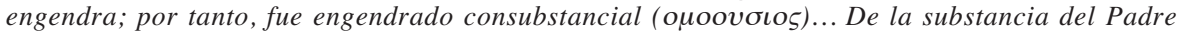
( $\varepsilon \kappa \tau \eta \varsigma$ ov $\iota \alpha \varsigma$ ). Según Simonnetti: "In polemica con i monarchiani egli rileva fortemente la sussistenza e la distinzione delle persone divine nell'ambito della Trinità mediante l'impiego di una terminologia che d'ora in avanti sarà acquisita alla teologia trinitaria d'Oriente: le tre persone

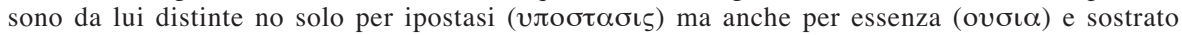
(vлокєциєvov) (La crisi, 11).

(124) También Arrio hablará de las hipóstasis, p. e. en Thalía (Atanasio, De synodis, 15; véase ib., 36), en carta a Alejandro (Atanasio, ib., 16). Respecto a Alejandro de Alejandría se expresa así Simonetti (La crisi, 60): "Lo possiamo definire un origeniano moderato, legato ancora in qualche modo ad Ario dalla comune affermazione che il Padre e il Figlio costituiscono due ipostasi, cioè due realtà sussistenti: ma, nell'ambito di questa ormai troppo generica piattaforma comune, nettamente opposto a quello circa il modo di presentare il rapporto fra le due ipostasi”. Véase, Kelly, Doctrines, 224-226. Cf. Alejandro, Ep. ad Alexandrum (de Tesalónica), 16; 19, etc. (Teodoreto, Hist eccl, I, 4). Véase además, p. e. Concilio de Antioquía del 341 (Atanasio, De synodis, 23).

(125) V. H. Drecoll (Die Entwicklung der Trinitätslehre des Basilius von Cäsarea. Sein Weg vom Homöusianer zum Neonizäner (Forschungen zur Kirchen- und Dogmengeschichte, 66), Göttingen 1996, p. 340) opina así en la conclusión de su investigación demasiado centrada en la literalidad de la fórmula: "Die Entwicklung des trinitätstheologischen Denkens des Basilius zeigt somit, wie die neonizänische Position sich Schritt für Schritt aus der rechtshomöusianischen entwickelt hat. Die homöusianische Position von 358, wie sie etwa Basilius von Ankyra vertrat, führte keineswegs automatisch zur neonizänischen Theologie. Basilius verfügte nicht ab Julians

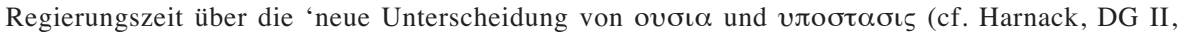

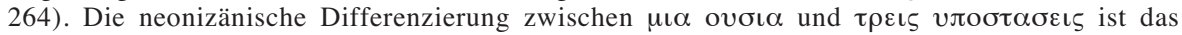
Ergebnis eines langen Prozesses, an dessen Anfang die Abwehr der anhomöischen Theologie und die Rezeption athanasianischer Gedanken stand und der in seinem Velauf vor allem durch den Zerfall der sich nach dem Tod des Konstantius in der Julian- und Jovianzeit wieder bildenden homöusianischen Partei und die Auseinandersetzung mit dem Pneumatomachentum geprägt wurde. Entscheidend ist, dass Basilius nicht von einer Drei-Hypostasen-Theologien herkommt, sondern vom Ansatz her dem athanasianischen Denken ziemlich nahe steht: Das Ergebnis des arianischen Streites ist deshalb nicht als Aufweichung der nizänisch-athanasianischen Position, sondern als begriffliche Präzisierung derselben anzusehen". 
ovoı́ (126) era lo común, y las tres hipóstasis se reconocían por lo propio del Padre, o del Hijo, o del Espíritu Santo respectivamente (127). O como dirá también Anfiloquio de Iconio, eran modos de subsistencia (

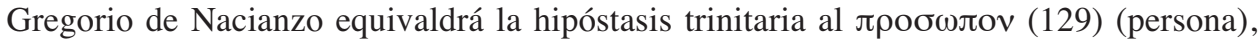

(126) Muchos han visto en esta concretud de la ovoı $\alpha$ divina, influencia platónica. Simonetti (La crisi, p. 518 n. 162; cf. ib., 541s), por su parte, afirma: "È comunque fuor di dubbio che i Cappadoci hanno inteso l'ousia divina non in senso formale, bensì come concreta, reale essenza divina: una ousia = una divinità". Otros han destacado influencia estoica, etc. (véase p. e. la recensión bibliográfica de A. M. Ritter, Il secondo Concilio ecumenico e la sua ricezione: stato de la ricerca (Cristianesimo nella storia 2(1981)341-368, pp. 361-365)). Respecto a la realidad concreta de la substancia una, puede verse también Kelly, Doctrines, 267-269.

(127) Cf. p. e. Ep 210, 5; 214, 4; 236, 6s; 38, 1-3.5 (¿Gregorio de Nisa?); De Spir S, XVIII, 45. Véase Basilio, C Eunomio, I, 19, 41-44; II, 28, 39-44, etc. Según Basilio, la única diferencia que puede existir en Dios es aquella que existe entre las causas y lo que de ellas deriva (C Eun, I, 23, 27). Puede verse Milano, op. cit., 127-145.

La distinción por lo común y lo propio entre la ovoı $\alpha$ y la hipostasis no se podrá aplicar tal cual a la Encarnación, cuando Calcedonia defina en Cristo una hipóstasis en dos naturalezas, porque la naturaleza humana de Jesús tiene propiedades y, por tanto, debería ser hipóstasis, además de la hipóstasis del Logos. Será el trabajo del neocalcedonismo redefinir más profundamente la hipóstasis como lo independiente. La naturaleza humana de Jesús no será hipostática en sí ( $\alpha \theta^{\prime} \varepsilon \alpha v \tau o$ ) sino en el Logos, porque no es independiente sino propia del Logos. De definir la hipótasis por su aspecto cognoscitivo (propiedades) se pasará a definirla por su aspecto ontológico, en parte gracias a la influencia de Proclo. En el estoicismo 'hipóstasis' siempre había tenido el doble aspecto, de manifestación y de concreción. Puede verse S. Zañartu, Algunos desafíos del misterio del Dios cristiano a las categorías del pensar filosófico en la antigüedad. $\Lambda o \gamma o \varsigma \varepsilon$

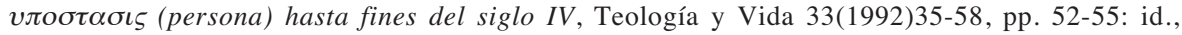
Reflexiones sobre la fórmula dogmática del concilio de Calcedonia, 171-175; P. Hünermann, Hypostase, hypostatische Union, col. 373-375, en LThK, $3^{\mathrm{a}}$ ed., V, 371-377.

(128) Frgm 15, PG 39, 112CD. Cf. p. e.: Basilio, De Spir S, XVIII, 46, 8; Teodoreto (?) Quaest et resp, 139, PG 6, 1392C-1393A; idem, Expos rect fidei, 3, PG 6, 1209B-1212B; Máximo, Myst, 23, PG 91, 701A; Juan Damasceno, De fide orth, I, 8, 115s.118.252.

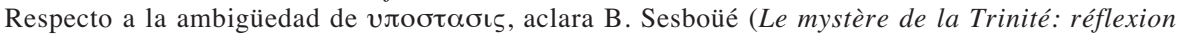
spéculative et élaboration du langange, p. 291s, en B. Sesboüé y J. Wolinski, Le Dieu du salut

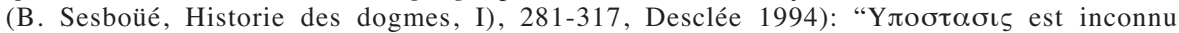
d'Aristote comme terme philosophique. Le mot entrera dans le champ de la philosophie grâce aux stoïciens. Son étymologie (de même que la manière dont on comprend son rapport avec les verbes

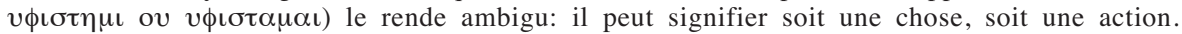
Comme chose, il exprime une base, un fondement, en histoire naturelle un sédiment, le résultat d'une précipitation, en général tout ce que se tient sous, donc tout réalité 'substantielle'. Dans cette ligne son emploi philosophique en fera un synonyme d'ovoı $\alpha$ ou substance. Comme action,

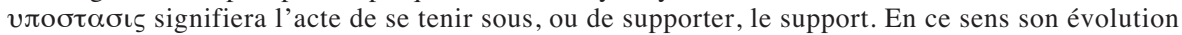

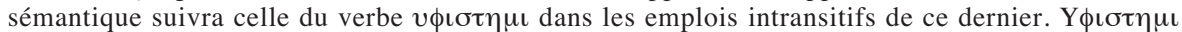
veut dire se tenir sous, mais aussi subsister, dans un sens tout voisin de celui d'vл $\alpha \rho \chi \omega$, exister.

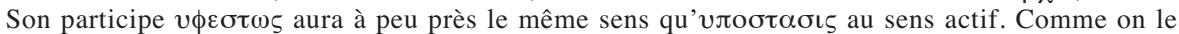
voit, l'usage philosophique de ce terme pouvait se développer selon deux lignes: la première

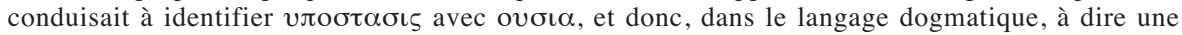

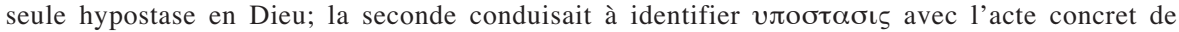
subsister dans la substance et donc à dire trois hypostases en Dieu. Au cours du développement du discours chrétien le terme va lentement passer du côté de la substance à celui de la subsistence et donc de la personne". Cf. J. Hammerstaedt, Hypostase, RAC XVI, col. 986-1035; P. Hünermann, Hypostase, hypostatische Union, LThK ( $3^{\mathrm{a}}$ ed.), V, col. 371-377.

(129) Or 42, 16. Respecto a la equivalencia en Basilio, puede verse, J. M. Yanguas Sanz, Pneumatología de Basilio. La divinidad del Espíritu Santo y su consubstancialidad con el Padre y con el Hijo, Pamplona 1983, p. 243s. Según B. Studer (Hypostase, en J. Ritter y K. Gründer, HWPh, III, 12551259, col. 1257), había alguna base para llegar a equivalerlos, porque de alguna manera ambos vocablos decían "Kundgabe der Wirklichkeit". La equiparación no quiere decir que los dos téminos

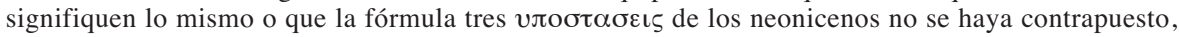
p. e. en Antioquía, a la tres $\pi \rho \circ \sigma \omega \pi \alpha$ de los viejos nicenos (cf. Halleux, Hypostase). "L'une 
que en griego se prestaba menos que en latín para designar a los tres, porque tenía más sabor a 'rostro' (o máscara) modalista. Esta diferencia se debía a que 'persona' en latín se había consolidado más como individuo por su uso jurídico (130). Así la fórmula

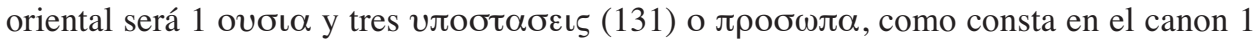
del concilio de Constantinopla II del 553. Como ya dijimos al principio, sabemos que el concilio de Constantinopla I afirmó 1 ov $\_\iota \alpha$ y 3 hipóstasis (o $\pi \rho \circ \sigma \omega \pi \alpha$ ) por la sinodal del año siguiente en referencia a este concilio. Y el anatematismo añadido al Credo de Nicea, en el que se identificaba ovoı $\alpha$ e hipóstasis, no aparece en el Credo del Constan-

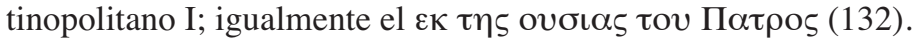

hypostase des vieux-nicéens désignait la substance, la nature ou l'essence de Dieu tout entière, risquant par là de reléguer les personnes dans le domaine de la manifestation économique, tandis que les néo-nicéens, visant la réalité ontologique de Dieu par les trois hypostases aussi bien que par l'ousie, allaient désormais devoir rendre compte de la distinction et du rapport de ces deux concepts en faisant appel, entre autres, aux catégories logiques aristotélico-stoïciennes du commun et du particulier ou de la relation, ainsi qu'à la métaphysique moyen et néo-platonicienne de l'union inconfuse d'êtres spirituels par leur totale interpénétration" (ib., 211).

(130) Sujeto de derecho

(131) El origen de esta fórmula capadocia es bastante discutido, y oscuro. Puede verse al respecto $\mathrm{M}$. Simonetti, Dal nicenismo al neonicenismo. Rassegna di alcune pubblicazioni recenti, Aug 38(1998)5-27. Afirma este autor: "io sono d'accordo con quegli studiosi che considerano essenziale, per la comprensione del dibattito trinitario del IV secolo, la distinzione di significato tra l'homoousios niceno, che predica una sola usia e una sola ipostasi del Padre e del Figlio in accezione sostanzialmente monarchiana, e l'homoousios costantinopolitano che, secondo l'interpretazione basiliana accolta dal padri conciliari, articola l'unica usia divina nelle tre ipostasi distinte di Padre Figlio e Spirito santo, modificando profondamente il significato della professione nicena alla luce della tradizione trinitaria divisiva di Origene ed Eusebio" (ib., 6s). Tempera en una nota su juicio sobre el homoousios de Nicea, en referencia al anatematismo, precisando: "la formula nicena poteva agevolmente, non doveva necessariamente, essere interpretata in senso monarchiano".

(132) Simonetti (La crisi, p. 94, n. 52) dice respecto al símbolo de Nicea: "Si protrebbe ravvisare forse una sfasatura nell'uso di ousia/homoousios nel simbolo: infatti ousia sembra adoperato tutte e due le volte in senso individuale (il Figlio è stato generato dalla ousia del Padre) in maniera da distinguere l'essenza del Padre rispetto al Figlio; invece homoousios sembra adoperato, sì, in senso individuale (sulla base dell'identificazione ousia=ipostasi), ma in maniera da comprendere anche il Figlio nella ousia paterna. Questa sfasatura potrebbe rispecchiare i contrasti che si ebbero nel concilio sull'argomento, alla formulazione definitiva. Ma si tenga anche presente che la derivazione del Figlio dalla ousia del Padre non implica necessariamente connotazione individuale del termine, come appar chiaro dall'uso che del termine e della formula fa Atanasio: il Figlio deriva dalla ousia del Padre, ma non è caratterizzato da ousia propia in quanto partecipe dell'ousia paterna". En este sentido, dada la aclaración de los Capadocios de que la ousia divina es común y única, sería lógico que desaparecieran del Credo las expresiones que la enfocaban ousia de manera más individualizante.

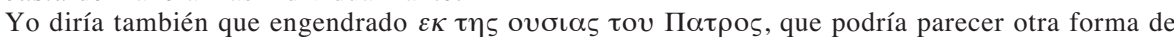
decir el opoovolos y que habría sido eliminado en Constantinopla I por ser repetitivo de este, pretendía en Nicea decir ( $\tau 0 v \tau \varepsilon \sigma \tau \iota v)$ : viene del Padre, 'como' de sus entrañas, teniendo, pues, su misma substancia (por engendramiento) (cf. Ortiz de Urbina, El símbolo, 133-140). Pero, identificando ovoı $\alpha$ con persona, podía leerse como que 'viene' de la 'persona' del Padre, así como el Espíritu Santo procede del Padre. Porque, de lo contrario, si 'venía' de la substancia, que es 'común', tendería a significar la partición de esta o iría en contra de lo que posteriormente declarará el concilio Lateranense IV (DH 804): la substancia no engendra ni es engendrada. Pero si por ovoı $\alpha$ se entendía la persona del Padre, podía refluir esto en una interpretación modalista del ouoovoıs (la misma persona). Dadas esta posibles malas interpretaciones y habiéndose establecido, a la altura del Constantinopolitano I, que ovoı $\alpha$ era lo común, la expresión no aparece en este Credo. Además complicaría el formular la procedencia del Espíritu, que también es de la misma substancia -ouoovolos, término ya usado por Atanasio y Gregorio de Nacianzo respecto a él, aunque no esté dicho en el Credo-, pero que no es Hijo. 
Ahora, profesar 3 hipóstasis era rechazar el modalismo. Recordemos también que en el canon 1 del Constantinopolitano I aparecen condenados los modalistas Marcelo de Ancira y Fotino, juntos con los sabelianos. Así el concilio de Constantinopla I fue equilibrado en cuanto condenó ambos extremos. Esto marcaba el final de la crisis arriana (subordinacionista) en Oriente. Oriente y Occidente coincidían, entonces, en fórmulas equivalentes. La fórmula oriental, con su respectiva profundización teológica, fue mérito especialmente de los neonicenos Capadocios, gracias a los ambientes homeousianos, gracias también a la discusión de la divinidad del Espíritu, que se produce más o menos a partir del 360. Afirmar y profundizar en la divinidad del Espíritu llevó el proceso trinitario a una culminación, que Agustín desarrollará posteriormente a partir de la categoría de relación, afirmada por los Capadocios.

\section{GREGORIO DE NACIANZO COMO UN EJEMPLO DE CULMINACIÓN DE LA EXPRESIÓN TRINITARIA}

Esta culminación se refleja, por ejemplo, en las Orationes Teológicas (Orat 27-31) de Gregorio de Nacianzo (133), predicadas en la misma Constantinopla poco antes del concilio del 381, a cuya contextuación e interpretación está dedicado este artículo. Proclamando, contra Eunomio, la incomprensibilidad de Dios (134), Gregorio se muestra como deslumbrado por el misterio de la Trinidad y unidad de Dios. Así brilla la afirmación de la Trinidad en su luz enceguecedora, como única es la fusión $(\sigma v \gamma \kappa \rho \alpha \sigma \iota \varsigma)$ de la luz en tres soles que se compenetran mutuamente (135). Los tres son luz: luz y luz y luz, pero una sola luz, un solo Dios (136). La divinidad del Espíritu ha llevado a que la Trinidad resplandezca con más brillo, o quizás, mejor traducido (137), resplandezca para almas más ilustres. Se ha producido, pues, como un deslumbramiento entre la unidad y la Trinidad (138): "Cuando, pues, por una parte miramos a la divinidad y a la causa primera y a la monarquía, se nos aparece lo uno, pero cuando miramos, por otra parte, hacia aquellos en los que está

(133) Cf. S. Zañartu, Presentación de algunos aspectos de la Trinidad en los discursos teológicos de Gregorio de Nacianzo, Teología y Vida 43(2002)436-464.

(134) Como ha dicho un griego, conocer a Dios es difícil, y expresarlo, imposible. A lo que Gregorio agrega: expresarlo es imposible y conocerlo todavía más imposible $(28,4)$. Captar a Dios sería limitarlo. Es una $\phi v \sigma \iota \varsigma \alpha \lambda \eta \pi \tau o \varsigma \tau \varepsilon \kappa \alpha \iota \alpha \pi \varepsilon \rho \iota \lambda \eta \pi \tau o \varsigma$. No respecto a su existencia sino a qué es

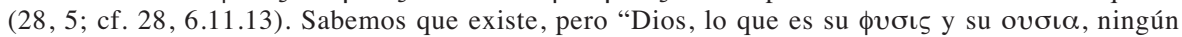
hombre lo ha descubierto jamás ni lo descubrirá" (cf. 28, 17; véase 28, 18.19.21; 31, 8), en esta

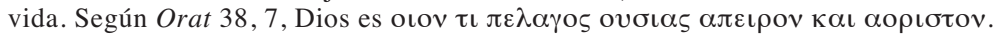

(135) 31,14 . Véase $31,28$.

(136) 31, 3. Confiado en la divinidad del Espíritu, ha aplicado las mismas voces a la Trinidad. Así aplica también Jn 1, 9 al Padre, y al Hijo, y al Paráclito. "Era y era y era, pero era uno (en)". Y concluye, a propósito del Sal 35, 10 (numeración de los LXX): "de la luz -el Padre-, captamos la luz -el Hijo-, en la luz -el Espíritu-, teología breve y simple de la Tríada”. Ha mostrado, pues, la igualdad de los tres, manteniendo que Dios es uno. Así exclama en sus versos: "Dios, Dios mío y Dios, mónada trina" (Carm II, 1, 14, 42, PG 37, 1248). Respecto a una comparación de la Trinidad, que le atrae pero critica, dice en 31,32: "no siendo uno más que muchos ni muchos más que uno".

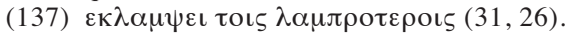

(138) El deslumbramiento entre los dos polos de Gregorio es reforzado por la lucha contra los dos extremos: sabelianos y arrianos. 
la divinidad y los que vienen de la primera causa atemporalmente y con igual gloria, adoramos a tres" (139). Esto se refuerza por lo que antes había dicho en este mismo párrafo: "un solo Dios, porque una sola divinidad. Y hacia la unidad ( $\pi \rho \circ \varsigma \varepsilon v$ ) se vuelve ( $\tau \eta v \alpha v \alpha \phi o \rho \alpha v \varepsilon \chi \varepsilon \iota)$ lo que viene de él, aunque sea creído que son tres. Porque el uno no es más Dios y el otro menos Dios; ni el uno es primero y el otro posterior. Ni se escinden en la voluntad, ni se dividen en el poder..., sino que la divinidad, si es necesario hablar brevemente, es sin división en los distintos ( $\alpha \mu \varepsilon \rho$ -

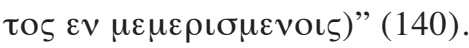

Gregorio tiende a poner el fundamento de la unidad en el Padre. En Orat 29, 2, diferenciando la monarquía no limitada a un $\pi \rho 0 \sigma \omega \pi o v$, de la anarquía y de la poliarquía, dice que ella está constituida de igual dignidad de naturaleza y acuerdo del querer e identidad del movimiento, y convergencia a la unidad de los que vienen de ella, de manera que, aunque haya diferencia por el número, no se divida en la substancia $\left(o v \sigma \iota \alpha_{\iota}\right)$. "Por esto, desde el comienzo la mónada (141), en movimiento ( $\iota \vee \eta \theta \varepsilon \iota \sigma \alpha)$ hacia la díada se ha detenido en la tríada (142). Y esto es para nosotros el Padre y el Hijo y el Espíritu Santo" (143).

Tratando de las "personas", Gregorio las presenta así en 30, 19: "El nombre propio del sin principio, es Padre; del engendrado de modo sin principio ( $\alpha \nu \alpha \rho \chi \omega \varsigma)$ (144), Hijo; del que de modo no engendrado ( $\alpha \gamma \varepsilon v \vee \eta \tau \omega \varsigma)$ prosigue ( $\pi \rho \circ \varepsilon \lambda \theta 0 v \tau o \varsigma)$

(139) 31, 14. Véase p. e. Orat 40, 41 ("no alcanzo (ov $\phi \theta \alpha \nu \omega)$ a pensar lo uno y estoy rodeado del esplendor de los Tres; no alcanzo a distinguir los tres y ya soy conducido a lo uno"). En Orat 6, 22 afirma Gregorio: “Adorando al Padre y al Hijo y al Espíritu Santo. Reconociendo en el Hijo al Padre, en el Espíritu al Hijo, en los que hemos sido bautizados, en los que hemos creído, con los que nos hemos alineados, distinguiendo antes de unir, y uniendo antes de distinguir ( $\pi \rho \imath$ ovv $\alpha-$

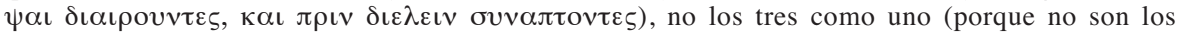

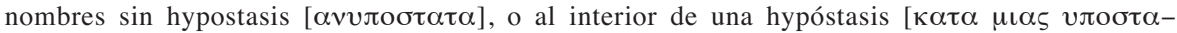
$\sigma \varepsilon \omega \varsigma]$, como si la riqueza para nosotros estuviera en los nombres y no en las realidades [ $\pi \rho \alpha \gamma-$ $\mu \alpha \sigma \iota])$, y los tres uno. En efecto, son uno, no por la hypóstasis sino por la divinidad. La mónada es adorada en la Trinidad y la Trinidad recapitulada en ( $\varepsilon\llcorner\varsigma)$ la mónada".

(140) Véase, p. e. Gregorio de Nisa, Ref conf fidei Eun, 6. Gregorio de Nacianzo en 31, 12, después de declarar que ir contra el Hijo es deshonrar al Padre, e ir contra el Espíritu es deshonrar al Hijo, pide que el oyente no mezcle nada de la Trinidad consigo mismo para que no se separe de la Trinidad. "No amputes nada a esta naturaleza única e igualmente venerable. Porque si sacas algo de los tres, serás destructor de todo, más bien tú quedarás fuera del todo". Por tanto, quitar algo a la Trinidad, que es un todo, es quitar algo a la única naturaleza (véase también, p. e., Orat 6, 11). Esto muestra claramente la identificación real de la única naturaleza con la Trinidad. Véase, p. e.,

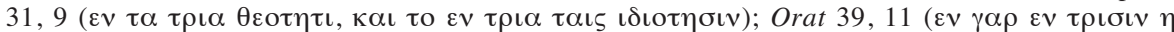

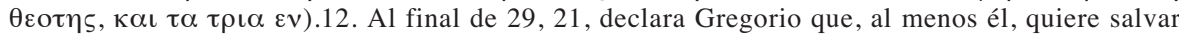
la Tríada para sí mismo y ser salvado por la Tríada.

Según Gregorio de Nisa (Orat Catech, III), la unidad de la naturaleza y la distinción de las hipóstasis es el camino medio entre el judaísmo y el politeísmo. Puede verse S. Zañartu, El Dios razonable de la Gran Catequesis de Gregorio de Nisa, Teología y Vida 45(2004)564-604, pp. 567-573.

(141) En 31, 18 se usa 'mónada' para unidades diferentes, aunque estén unidas por la substancia (sean consubstanciales)

(142) "La mónada se pone en movimiento en virtud de su riqueza, se sobrepasa la díada..., se limita en la tríada por la perfección, que es la primera en sobrepasar la composición de la díada, de manera que la divinidad no permanezca estrecha ni se esparza al infinito" (Orat. 23, 8). Lo primero sería judío; lo segundo helénico y politeísta. Según Orat 38, 8, Dios es Padre, Hijo y Espíritu, para no judaizar mediante la monarquía, y para no helenizar mediante la sobreabundancia (pueblo de dioses).

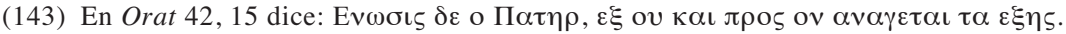

(144) Equivale aquí a eternamente. 


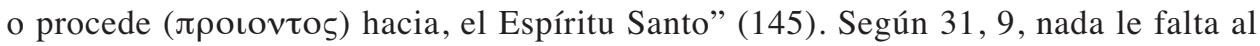
Espíritu, nada le falta al Hijo. La diferencia de la manifestación o de la relación entre ellos ha hecho también la diferencia en el nombre. La filiación no es una carencia. Tampoco se trata de una inferioridad ( $\phi \varnothing \varepsilon \sigma \varepsilon \omega \varsigma)$ según la substancia. "El

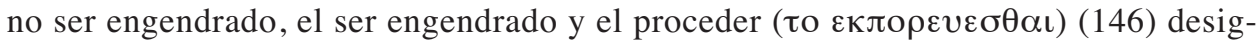
nan al Padre, y al Hijo, y al Espíritu Santo, del que aquí se habla, para que sea

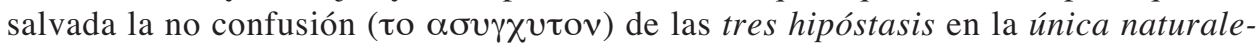
za y dignidad de la divinidad. Porque ni el Hijo es el Padre, pues hay un solo Padre, sino lo que es el Padre, ni el Espíritu es el Hijo por (venir) de Dios, pues hay un solo Unigénito, sino lo que es el Hijo. Los tres son uno en la divinidad y lo uno es tres en las propiedades" (147). Y, respecto a la acción trinitaria sobre nosotros, había dicho en 28, 1: "Pongamos en la cabeza de este discurso al Padre y al Hijo y al Espíritu Santo, sobre los que es el discurso, de forma que el primero sea benevolente ( $\varepsilon v \delta o-$ $\kappa \varepsilon \iota v)$, el segundo coopere ( $\sigma v v \varepsilon \rho \gamma \varepsilon \iota \nu$ (148)) y el tercero inspire ( $\varepsilon \mu \pi v \varepsilon \iota v)$, o más bien que se haga una única iluminación de la única divinidad, unitariamente distinta

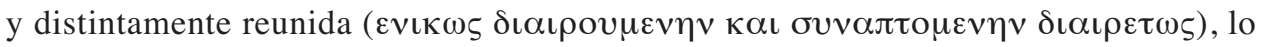
que es paradojal" (149).

Finalmente, Gregorio compara, en su primera carta a Cledonio, la verdad cristológica y la trinitaria, de la siguiente manera: "Y para decirlo brevemente, lo uno y lo otro, de lo que está [formado] el Salvador... y no el uno y el otro. ¡Lejos de eso! Porque ambas cosas son uno por la unión ( $\sigma v \gamma \kappa \rho \alpha \sigma \varepsilon \iota)$ (150), Dios que se hace hombre y el hombre que se hace Dios, o como se lo quiera nombrar. Pero digo lo uno y lo otro, contrariamente a lo que tiene lugar en la Trinidad. En esta (decimos), por una parte, el uno y el otro para que no confundamos las hypóstasis; y no, por otra parte, lo uno y lo otro, porque los tres son uno y lo mismo por la divinidad" (151).

(145) "Todo cuanto es el Padre, es del Hijo, salvo el ser ingénito. Todo cuanto es el Hijo, es del Espíritu, salvo el ser engendrado. Todo esto no divide la substancia sino que se divide $\pi \varepsilon \rho \iota$ ovouav" (Orat 41,9).

(146) Cf. también 29, 2.3; 31, 8. En 29, 2 el Espíritu es llamado $\pi \rho o \beta \lambda \eta \mu \alpha$ en relación al Padre $\pi \rho \circ \sigma \beta o \lambda \varepsilon v \varsigma$, quien respecto al $\gamma \varepsilon v v \eta \mu \alpha$ es 1 lamado $\gamma \varepsilon v \nu \eta \tau \omega \rho$. Según 29,3 , el Hijo no procede (о $\kappa \varepsilon \kappa \pi \varepsilon \pi о \rho \varepsilon v \tau \alpha \iota)$, sino que ha sido engendrado $(29,3)$. Según Orat 39, 12, el Espíritu proce-

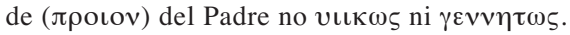

(147) Véase también 31, 28.

(148) Véase $30,3.5$.

(149) Cf. Orat 23, 8. Dice, contrastando el Creador con la creatura, en Orat 34, 8: "Lo primero se llama Dios, aunque consiste en los Tres grandísimos, la Causa, el Demiurgo y el que hace perfecto $\left(\tau \varepsilon \lambda \varepsilon\left\llcorner\right.\right.$ เоль $\omega_{\imath}$ ) (véase, p. e. Orat 38, 9; 41, 9.11; Basilio, De Spir S, XVI, 38, etc), yo digo el Padre y el Hijo y el Espíritu Santo. ...es más uno $(\varepsilon \vee \iota \kappa \omega \tau \varepsilon \rho \alpha)$ que lo del todo divisible y más rico que lo perfectamente mónada". Véase p. e. Orat 23, 8; 25, 17; 26, 19; 39, 11. Gregorio de Nisa indica lo personal en la unitaria acción común ad extra, por ejemplo, de esta manera: "Oyendo al Padre, oímos la causa de todo; instruyéndonos sobre el Hijo, somos enseñados respecto a la

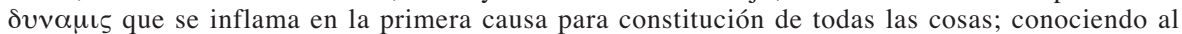
Espíritu, comprendemos la $\delta v v \alpha \mu \iota \varsigma$ perfeccionante de lo traído a ser mediante la creación a partir del Padre mediante el Hijo (Ep 24, 4).

(150) Véase p. e. Ep 101, 13-15.

(151) Ep 101,20s. 


\section{EL ASPECTO NEGATIVO}

Pero este proceso de expresión y profundización teológica en el siglo de oro de los Padres, tuvo su costo: puso las bases para un teología de la Trinidad en sí, descuidada de lo económico. Antes, con los peligros, modalista y subordinacionista por lado y lado, la Trinidad estaba de sí más conectada con el mundo, con nuestra salvación (152). Creo que los dos principales paradigmas de pensamiento humano en que se había expresado la fe neotestamentaria, ambos provenientes del A. T., fueron: el del mesías exaltado sentado en el trono con Dios, y el del 'desdoblamiento', por así llamarlo: el trascendente actúa en la inmanencia del mundo por medio de su Espíritu, Palabra, Sabiduría, Hijo. En uno y otro se conservaba la unidad, la monarquía, porque el Hijo hace todo y solo lo que el Padre le ha ordenado, porque hay una mutua inmanencia entre los dos, porque el Hijo y el Padre son uno. Y ambos implican una fuerte relación al mundo, a nuestra salvación. Pero después de los concilios trinitarios del s. IV, si los tres son consubstanciales, la unidad reluce en esa substancia (153) (lo que puede derivar al tratado De Deo uno); y la distinción, en la oposición de relaciones, haya o no creación e historia de salvación. El tratado sobre la Trinidad se puede apartar así de los otros tratados.

A esto corresponderá un nuevo paradigma en Occidente, que es brillante, como lo vemos en Agustín y Tomás, pero es 'intelectual', como un poco el Quicumque. Este cambio de paradigma (de lo económico a lo intelectual) desvitalizará, para muchos, el tratado sobre la Trinidad. Autores actuales llegarán a hablar del destierro de la Trinidad. El concilio Vaticano II, en su enfoque pastoral, es un concilio profundamente trinitario y vital (154). Pero constatamos que no usó el lenguaje del paradigma intelectual, sino el neotestamentario y patrístico pastoral. Muchos actualmente buscan la vitalización del tratado trinitario bajo el aspecto de la Trinidad como comunidad perfecta (communio), modelo de la comunidad eclesial y humana,

(152) Cf. Simonetti, La crisi, 518s; A. Grillmeier, Jesus der Christus im Glauben der Kirche. II, 1: Das Konzil von Chalcedon (451). Rezeption und Widerspruch (451-518), $2^{\mathrm{a}}$ ed., Freiburg 1991, p. 5; Wolinski, op . cit., 142-145. Puede verse S. Zañartu, La monarquía del Padre, Anales de Teología (U. C. de la Santísima Concepción) 1(1999)115-131. Este artículo (bajo el número 9), como todos los otros citados del mismo autor, puede consultarse en la página web de la Facultad de Teología de Chile (www.puc.cl/teologia), en Cuerpo Docente, bajo su nombre. A de Halleux (La réception, 32) llega a expresarse así: "Désormais la pleine divinité du Fils et sa séparation radicale d'avec le cosmos se trouvaient nettement affirmées, même si le souci, alors bien légitime, de sauvegarder la consubstantialité des personnes divines allaient malheureusement conduire à sacrifier un 'subordinationisme orthodoxe' suggéré par l'évangile lui-même, ainsi qu'à dissocier la Trinité immanente de l'économie du salut, deux défauts auxquels la théologie s'efforce depuis lors de remédier sans trop bien y parvenir".

(153) "The result of this insistence on the identity of the ousia is seen in the changing emphasis with which the doctrine of the monarchy now comes to be regarded. There is no longer any suggestion that God is one simply by reason of the fact that the second and third Persons may in the last resort be resolved back into the first Person, since they derive their origin from Him. The fact that now comes to be emphasised is that the Father is manifested in the Son and in the Holy Spirit wholly and without any detraction. The three Persons no longer lead back to a unity that is primarily found in one Person; they are in a real sense one in themselves" (una mónada en la tríada y una tríada en la mónada) (Prestige, op. cit., 233). Los Orientales destacarán la unidad en la $\pi \varepsilon \rho \iota \chi \omega \rho \eta \sigma \iota \varsigma$.

(154) Cf. S. Zañartu, Algunas impresiones sobre la Trinidad en el Vaticano II, Teología y Vida 43(2002)580-601, pp. 581-585. 
aplicando una analogía conceptual de proporcionalidad que no destaca bien la trascendencia, la que queda más bien relegada al tratado De Deo uno. Los paradigmas prenicenos, en cambio, además de ser más económicos, denotaban mejor la trascendencia de Dios, al acentuarla en el Padre, a quien nadie ha visto, siendo Cristo su imagen (155) y el Espíritu su don (156).

\section{PALABRAS FINALES}

En conclusión de estas simples anotaciones, que solo pretenden bosquejar algo de la complejidad y riqueza doctrinal de lo vivido por la teología en el siglo IV y plasmado en el Constantinopolitano I, hemos visto que este último fue un concilio oriental, el concilio decisivo para la expresión del dogma trinitario, como lo será Calcedonia para el cristológico, aunque este último culmine en el Constantinopolitano III de 680-681. Lo decisivo se debe a haber llegado a un equilibrio ante los dos extremos, y a incluir al Espíritu Santo, conformando así la plenitud de la Trinidad. Esto se expresa en el Credo, canon 1 y en la fórmula capadociana. Con razón su Credo (griego) es el básico de las Iglesias cristianas, que se distinguen de las otras religiones justamente por su fe trinitaria. Tenemos la esperanza que las Iglesia católica y ortodoxa reconozcan mutuamente sus expresiones de fe respecto al proceder del Espíritu Santo, como ya lo adelantaron en el concilio de Florencia (157).

La proclamación de la divinidad del Hijo va íntimamente conectada con el misterio de su encarnación (158). Por eso en Nicea se anatematiza que el Hijo sea

(155) Orígenes y los alejandrinos presentarán al Logos invisible como imagen del Padre.

(156) Cf. S. Zañartu, Algunas reflexiones de conjunto sobre el misterio del Dios uno y trino, Teología y Vida 42(2001)468-489, pp. 468-475; idem, Trinidad y mundo plural. Algunas elucubraciones, Teología y Vida 42(2001)327-347, pp. 337-345.

(157) Es notable en este sentido el documento, ya citado, Les traditions grecque et latine concernant la procession du Saint Esprit.

(158) Según Hanson (op. cit., cap. 4), el arrianismo podría fluir desde una perspectiva soteriológica. Así expresa: "We can now perceive the rationale of Arianism. At the heart of the Arian Gospel was a God who suffered. Their elaborate theology of the relation of the Son to the Father which so much preoccupied their opponents was devised in order to find a way of envisaging a Christian doctrine of God which would make it posible to be faithful to the Biblical witness to a God who suffers. This was to be achieved by conceiving of a lesser God as reduced divinity who would be ontologically capable, as the High God was not, of enduring human experiences, including suffering and death" (ib., 121). Por su parte, R. C. Gregg y D. E. Groh (Early Arianism. A View of Salvation, London 1981, p. 8) opinan: "Salvation, for orthodoxy, is effected by the Son's essential identity with the Father -that which links God and Christ to creation is the divine nature's assumption of flesh. Salvation for Arianism is effected by the Son's identity with the creatures that which links Christ and creatures to God is conformity of will. Thus the Arians instinctively gravitated to those scriptural texts and exegetical perspectives which emphasized the empirical commonality of the redeemer's characteristics with those of all other creatures. Athanatius' party from the beginning of the controversy instinctively leaned toward showing the difference or distinction between the redeemer's characteristics and ours". Y hacia el final (ib., p. 170) dirán: "In short, we are suggesting that the setting of Arianism can best be found by researches who focus on those areas where the redeemer is understood to be a perfected creaturely model for us, where obedience to the will of God and progress in virtue are the operative categories for both Christology and soteriology, and where biblical and classical notions of wisdom have high currency". Respecto al nuevo enfoque soteriológico de esta y otras obras sobre el arrianismo primitivo, cf. A. M. Ritter, Arius redivivus? Ein Jahrzwölft Arianismusforschung, ThR 55(1990)153- 
cambiable o mudable. Y, contra las objeciones arrianas distinguen los ortodoxos lo que se dice de Cristo en cuanto Dios de lo que se dice en cuanto hombre (159), pero para esto último se necesitará aceptar, contra los arrianos, un alma humana en Jesús salvador (160). Un alma que explique su temor, angustia, etc. y que haga integral nuestra salvación, porque lo no asumido no es salvado (161). Por negar ese vovs humano va a ser condenado en el canon 1 del Constantinopolitano I Apolinar de Laodicea, por otro lado gran defensor de Nicea y amigo de Atanasio. Contra Apoli-

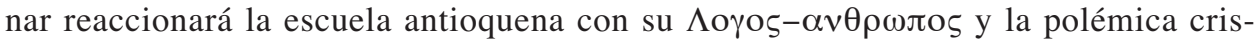
tológica seguirá llenando los siglos siguientes (162). Desde el punto de vista de Cristo nuestro mediador, en Nicea se afirmó su plena divinidad, y en la condenación de Apolinar su plena humanidad. Pero faltaba precisar más el misterio de su unión hipostática. Así como la Trinidad económica implica la Encarnación, así la Encarnación implica a la Trinidad. Es lamentable que en la enseñanza de la teología se hayan separado estos dos tratados, desvitalizando a la Trinidad, y exponiendo con menor profundidad la Cristología (163). Más aún si se sigue la sentencia de Tomás de que cualquiera de las tres personas podía absolutamente encarnarse.

187, pp. 156-162, et passim. Lorenz, en la conclusión de su libro ya citado, llega a afirmar: "Die Lehre von der präexistenten Seele des Erlösers ist die Stelle, wo Origenes die adoptianistischen Überlieferungen, deren Anwendung auf den Logos er ablehnte, in sein System eingebaut hat... Und von hier aus wird auch verständlich, warum Lukian und Arius den 'Logos' als Seele im seelenlosen Leib des Menschgewordenen betrachten. Der Arianismus ist keine Verschärfung des Subordinationismus der origenistischen Logoslehre, sondern der Ersatz der origenistischen Logoslehre durch die origenistische Christuspsyche. Erst Arius hat diese Lehre in klar durchdachten formeln dargelegt -sonst wäre der arianische Streit schon eher ausgebrochen- und mit logischer Begründung versehen... Die Verselbständigung der origenistischen Jesusseele bei Arius gab den adoptianistischen Gedanken, welche Origenes verwendet, aber unschädlich gemacht hatte, neuen Auftrieb. Darin liegt die Erklärung für die oben getroffenen Festellungen, dass die Christologie des Arius 'von unten', vom Menschen Jesus her gedacht ist und Verwandtschaft mit judenchristlicher Christologie aufweist” (p. 223)

(159) Véanse, por ejemplo, los contrates entre lo divino y lo humano de Cristo, en Gregorio de Nacianzo, Orat 29, 19s (lo que era permaneció; lo que no era asumió).

(160) Nicea, obnubilado por la negación de la divinidad del Hijo y dentro del contexto predominante de

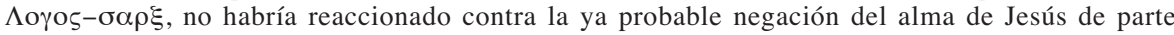
del mismo Arrio, aunque haya puesto en su Credo $\varepsilon v \alpha v \theta \rho \omega \pi \eta \sigma \alpha v \tau \alpha$. A la altura del Credo de Constantinopla, $\varepsilon v \alpha v \theta \rho \omega \pi \eta \sigma \alpha v \tau \alpha$ ya la debió incluir con claridad, dada la condenación de Apolinar. Cf. A. Grillmeier, Cristo en la tradición cristiana. I: Desde el tiempo apostólico hasta el concilio de Calcedonia (451) (Verdad e Imagen, 143), trad de $3^{\mathrm{a}}$ ed., Salamanca 1997, pp. 412423

(161) Cf. Gregorio de Nacianzo, Ep 101, 32

(162) La escuela de Alejandría corregirá el silencio de Atanasio sobre el alma de Cristo, afín a la

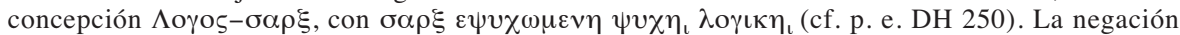
de que el cuerpo del Salvador fuera $\alpha \psi v \chi o v, \alpha v \alpha \iota \sigma \theta \eta \tau o v, \alpha v o \eta \tau o v$ en el $T$ ad Antioch, 7, firmado por Atanasio, podrá ser también utilizada por Apolinar de Laodicea para expresar su herejía (Ep ad episc in Diocesarea, 2, Lietzmann, p. 256). Véase, respecto a Vital, Epifanio, Haer, 77, 23. Según opinión de Hanson (op. cit. 643), "it is much more likely that these words in the Tomus were designed to condemn Arianism".

(163) Por providencia de Dios, a mí me ha tocado enseñar durante muchos años los dos tratados como uno solo. 


\title{
RESUMEN
}

Este concilio oriental, que terminó con la crisis arriana gracias a la nueva fórmula trinitaria de los Capadocios y al apoyo de Teodosio, confesó la divinidad del Espíritu Santo con términos equivalentes, como que procede del Padre y no por generación, pero dejó una puerta entreabierta para la futura controversia sobre el Filioque. Equilibró el ouoovoıs de Nicea con

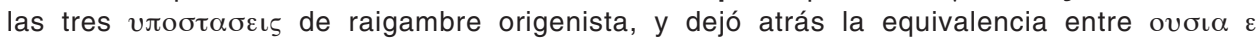

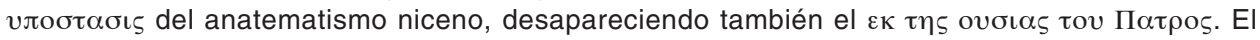
Hijo y el Espíritu pertenecen, pues, a la divinidad y no a la creación. Así Gregorio de Nacianzo, el teólogo, queda deslumbrado ante el misterio de la unidad y la Trinidad. Es el fin de la interpretación subordinacionista a que tendía la antigua cultura platónica o estoica. En ese sentido, la Trinidad, y no solo el Padre como pretendía el transcendentalismo de Arrio, se ha separado del mundo. Pero esto afecta a los paradigmas bíblicos que regían hasta entonces para concebir la Trinidad: entronización mesiánica, desdoblamiento entre Dios y su Palabra, Sabiduría, Espíritu. La unidad tenderá a colocarse ahora en la substancia y la distinción en la oposición de relaciones, como desarrollarán sobre todo Agustín y Tomás. Esta intelectualización, de menor raigambre económica, llevará a una desvitalización del tratado sobre la Trinidad.

Palabras clave: Constantinopla I, arrianismo, Espíritu Santo, Trinidad, consubstancial.

\begin{abstract}
This Eastern Council, which ended the Arian crisis thanks to the new Trinitarian formula of the Cappadocians and with the support of Theodosius, confessed the divinity of the Holy Spirit in terms of equivalency, as proceeding from the Father and not by generation, but it left a door partially open for the future controversy regarding the Filioque. The Council balanced the

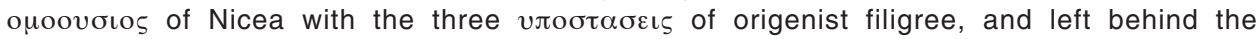

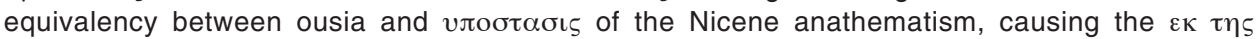

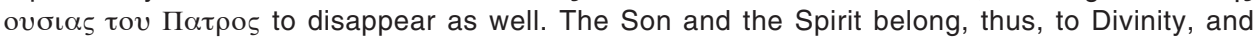
not to Creation. In this way, Gregory of Nazianzus, the theologian, ends up enthralled before the mystery of unity and Trinity. It is the end of the subordinationist interpretation to which the ancient Platonic-Stoic culture tended. In this sense, the Trinity, and not only the Father (as Arian transcendentalism postulated) has been separated from the world. But this affects those biblical paradigms for conceiving of the Trinity that were in effect up until then: Messianic enthronement, separation among God and his Word, Wisdom, Spirit. Unity will tend to be placed from now on in substance and distinction in opposition of relationships, as developed above all by Augustine and Thomas. This intellectualization, less economically-based, will bring about a deadening of theological treatises on the Trinity.
\end{abstract}

Key words: Constantinople I, Arians, Consubstantial, Trinitarian Formula, Divinity of the Holy Spirit 
